\title{
INTERACTION EFFECT OF DIETARY CRUDE PROTEIN AND ORGANIC ACIDS ON GROWTH PERFORMANCE, CARCASS CHARACTERISTICS AND IMMUNE ORGANS OF BROILER CHICKS
}

\author{
Faten M. Attia ${ }^{*}$, H.S. Abd El-Haliem, H.S. Saber and I. H. Hermes \\ Animal Production Department, Faculty of Agriculture, Suez, Canal University, Ismailia 41522, Egypt \\ "Corresponding author; Email: famattia@yahoo.com
}

(Received 1/2/2018, accepted 13/3/2018)

\section{SUMMARY}

\begin{abstract}
A $\mathrm{n}$ experiment was designed to investigate the effect of feeding two crude protein levels (PL): Required protein level (RPL), 2\% lower (LPL) and two organic acids (OA; citric, CA and fumaric, FUA) each at $0,1.5$ and $3 \%$ of the diet on the productive performance of broiler chicks (0-6 wks of age). Two hundred eighty-eight one-day old unsexed chicks (Cobb 500) were randomly divided into 12 treatments of 3 replicates ( 8 chicks each). Three types of corn-soybean meal diets were fed. Starter diet (0-3 wks of age; contained 23 and $21 \%$ crude protein, CP), grower diet (4-5 wks of age; contained 20 and $18 \% \mathrm{CP}$ ) and finisher diet (the $6^{\text {th }}$ wk of age; contained 18 and $16 \% \mathrm{CP}$ ). Diets were formulated to be isocaloric (3200 Kcal/Kg diet). Average daily gain (ADG) and average daily feed intake (ADFI) were significantly increased for most periods with RPL diets. Feed and caloric conversion ratios (FCR and CCR) were significantly improved with RPL (starter) or LPL diets (finisher). Crude protein conversion ratio $(\mathrm{CPCR})$ was improved $(\mathrm{P}<0.05)$ with LPL diets during all periods. Dressing, meat $\%$, and meat to bone or fat ratios were increased $(\mathrm{P} \leq 0.05)$ and abdominal fat $\%$ was decreased with RPL diets while LPL diets increased bursa and proventriculus \%. Bursa \% was significantly increased due to CA addition. The highest ADFI and the worst $(\mathrm{P} \leq 0.05)$ FCR, CPCR and CCR were recorded with $0 \%$ OA diets compared with $1.5 \%$ or $3 \%$ diets. The highest significant dressing $\%$ and meat: fat ratio and the lowest $(\mathrm{P} \leq 0.05)$ abdominal fat $\%$ were obtained with $1.5 \%$ OA diets. Diets supplemented with $3 \%$ OA significantly improved thymus \%. Significant differences in growth performance and carcass criteria due to the combined effects of PL, OAT and OAL were obtained. Diet of RPL+ 1.5\% CA increased $(\mathrm{P} \leq 0.05)$ ADG (starter and finisher), percentages of giblets, liver, dressing, meat: fat ratio and decreased abdominal fat. However, RPL+1.5\% FUA diets significantly improved ADG (grower and total periods), FCR, CPC and CCR. The highest values of thymus and bursa were reported with RPL+ 3\% CA diet. No mortality was recorded with RPL or LPL+1.5 CA or FUA diets.
\end{abstract}

Keywords: poultry; organic acids; protein levels; nutrition; productive performance.

\section{INTRODUCTION}

The poultry industry in Egypt has become one of the biggest agriculture industries and its improvement is one of the main goals of both private and public sectors. The intensive meat-type of poultry production increased from 118.8 million birds at the end of 2000 to 137.2 million birds by the end of 2010 (FAO, 2012). It is well-known that feeding cost for broiler is usually considered the most expensive item (70-75\% of the ongoing daily costs), especially dietary protein sources.

Efforts to reduce dietary protein level have been the subject of many investigators. Low protein diets are more profitable and have less impact on environmental pollution. In recent years, the high price of protein sources as well as environmental concerns, related to high nitrogen excretion, have resulted in increasing the interest of using low protein diets in broiler chickens production. Dehghani-Tafti and Jahanian (2016) reported that $2 \%$ of crude protein (CP) level in broiler diet could be reduced if the most limiting amino acids are provided at sufficient levels. However, Ragab et al. (2012) concluded that lowering CP level resulted in a reduction in the productive performance of chickens.

The use of antibiotics (growth promoters) as feed additives creates a great concern for environmental safety and consumer's health. Therefore, nutritionists are trying to substitute those with different natural 
feed additive materials, such as probiotics and/or organic acids (OA). Organic acids and their salts are considered safe additives and have been approved by most members of the European Union as feed additives in poultry nutrition with inclusion rates between 0.1 and $2 \%$. The positive effects of using OA on productive performance of young chicks include their roles in controlling all beneficial and harmful enteritis bacteria (Wolfenden et al., 2007) were reported. Also, they have positive effects on the immunity systems, intestinal morphology and energy and protein utilization (Houshmand et al., 2012). Additionally, Ghazalah et al. (2011) and Ragab et al. (2012) noticed that nutrient digestibility, growth, feed conversion ratio and vitality were improved by OA supplementation. Similarly, Fascina et al. (2012) stated that OA has growth-promoting properties and can be used as alternatives to antibiotics. Besides, Adil et al. (2010) indicated that the OA supplementation had positive outcome on the performance, irrespective of the type and level of acid used and may be exploited as growth promoters for broiler chicks. Antimicrobial additives growth-enhance effects become obvious when chickens are under suboptimal conditions, such as a less digestible diet or a less clean environment. Thus OA may be more efficient when low nutrient diets were fed (Hernández et al., 2006).

The effect of OA on broilers performance has been studied extensively; however, the interactive effect of dietary crude protein levels and supplemental OA types and levels was unreachable. Thus the aim of the present study was to investigate the effects of feeding two types of OA (citric and fumaric) at different concentrations with two levels of dietary crude protein on productive performance of broiler chicks.

\section{MATERIALS AND METHODS}

\section{Management and treatments}

The present study was carried out at the Poultry Research Farm, Department of Animal Production, Faculty of Agriculture, Suez Canal University, Ismailia, Egypt. Two hundred eighty-eight one-day old unsexed "Cobb 500" broiler chicks were obtained from a commercial hatchery. Chicks were wingbanded, weighed individually and randomly distributed into 12 treatments $\times 3$ replicates of 8 chicks each. The average initial live body weight of birds was almost similar $(49.75 \pm 0.19 \mathrm{~g})$. Chicks were raised in an open house and caged in brooder batteries with wire mesh floors. Feed and fresh water were supplied $a d$ libitum during the experimental period (6 weeks). The artificial light was provided daily for $23 \mathrm{hr}$ and one $\mathrm{hr}$ of darkness throughout the experimental period. Birds were kept in the same management, hygienic and environmental conditions and were vaccinated against the regular poultry diseases.

Two levels of CP [NRC 1994 required protein level (RPL) and 2\% lower (low protein level, LPL)] and two types of OA (citric, CA and fumaric, FUA) each at 0,1.5 and 3\% of the diet were studied. Chicks were fed three types of corn-soybean meal diets in mash form. Starter diet (0 to 3 weeks of age; contained 23 and $21 \% \mathrm{CP}$ ), grower diet (3 to 5 weeks of age; contained 20 and $18 \% \mathrm{CP}$ ) and finisher diet (the $6^{\text {th }}$ week of age; contained 18 and $16 \% \mathrm{CP}$ ). Diets were formulated to be isocaloric (3200 Kcal ME/Kg diet). The composition, calculated and determined chemical analysis (A.O.A.C, 1990) of all different diets for starter, grower and finisher phases are shown in Table $(1 ; \mathrm{a}, \mathrm{b}$ and $\mathrm{c})$.

\section{Growth parameters}

Individual live body weight and feed intake for each replicate were recorded weekly using a sensitive digital scale. Average daily gain (ADG), average daily feed intake (ADFI) per chick, feed conversion ratio (FCR), crude protein conversion ratio (CPCR) and caloric conversion ratio (CCR) were calculated. Birds were observed daily for mortality and the accumulative mortality rate was recorded.

\section{Slaughtered parameters}

At the end of the experiment (6-week of age), two birds were chosen close to the average body weight from each replicate ( $\mathrm{six}$ birds per treatment). Birds were kept fasted of food overnight with free access to water. Selected birds were individually weighed, slaughtered, bleed for 3-5 minutes and feathered. Inedible parts (blood, feather, head, legs and viscera), dressing, giblets and abdominal fat (F) were individually weighed. Proventriculus, gizzard, liver, intestine, spleen, thymus gland and bursa of fabricius were individually weighed and intestine length $(\mathrm{cm})$ was measured. Each eviscerated carcass was deboned; meat (without skin) and bone were weighed. Meat (M) to bone (B) and meat to fat ratios were calculated. All measurements mentioned above were expressed as a percentage of live body weight of chosen birds except meat and bone were expressed as a percentage of eviscerated carcass weight. 
Table (1, a). Formulation and chemical analysis (calculated and determined) of broiler starter diets (0-3wk).

\begin{tabular}{|c|c|c|c|c|c|c|}
\hline Diets (CP \%) & \multicolumn{3}{|c|}{23 (Required protein level) } & \multicolumn{3}{|c|}{21 (Low protein level) } \\
\hline \multicolumn{7}{|l|}{ Ingredients $\%$} \\
\hline Yellow corn & 52.13 & 50.00 & 50.00 & 57.21 & 55.80 & 53.00 \\
\hline Soybean meal $44 \%$ & 29.44 & 29.05 & 23.97 & 26.80 & 24.75 & 24.40 \\
\hline Corn glu. Meal 60\% & 9.65 & 10.00 & 13.70 & 7.50 & 9.10 & 10.00 \\
\hline Veget.oil & 4.70 & 5.35 & 5.10 & 4.30 & 4.70 & 5.40 \\
\hline Limestone & 1.41 & 1.40 & 1.41 & 1.50 & 1.41 & 1.45 \\
\hline Di-Ca phosphate & 1.68 & 1.70 & 1.75 & 1.72 & 1.74 & 1.76 \\
\hline${ }^{1}$ Vit.+ min. premix & 0.30 & 0.30 & 0.30 & 0.30 & 0.30 & 0.30 \\
\hline $\mathrm{NaCl}$ & 0.40 & 0.40 & 0.40 & 0.40 & 0.40 & 0.40 \\
\hline DL- Methionine & 0.10 & 0.10 & 0.06 & 0.09 & 0.08 & 0.07 \\
\hline L-Lysine $\mathrm{HCl}$ & 0.09 & 0.10 & 0.21 & 0.08 & 0.12 & 0.12 \\
\hline Choline chloride & 0.10 & 0.10 & 0.10 & 0.10 & 0.10 & 0.10 \\
\hline${ }^{2}$ Organic acid level & 0 & 1.50 & 3.00 & 0 & 1.50 & 3.00 \\
\hline Total & 100 & 100 & 100 & 100 & 100 & 100 \\
\hline \multicolumn{7}{|l|}{ Calculated values\% } \\
\hline ME (Kcal/Kg) & 3208 & 3203 & 3204 & 3202 & 3206 & 3205 \\
\hline Crude protein & 23.51 & 23.28 & 23.52 & 21.16 & 21.09 & 21.24 \\
\hline Lysine & 1.108 & 1.104 & 1.105 & 1.018 & 1.013 & 1.005 \\
\hline Methionine & 0.518 & 0.517 & 0.502 & 0.467 & 0.466 & 0.462 \\
\hline Meth+Cystine & 0.911 & 0.907 & 0.900 & 0.829 & 0.831 & 0.829 \\
\hline Calcium & 1.001 & 1.000 & 1.001 & 1.037 & 1.002 & 1.020 \\
\hline Available Phosphorus & 0.450 & 0.450 & 0.451 & 0.451 & 0.450 & 0.451 \\
\hline \multicolumn{7}{|l|}{ Determined values\% } \\
\hline Moisture & 8.14 & 8.14 & 8.47 & 8.33 & 8.21 & 8.00 \\
\hline Crude protein & 22.90 & 22.75 & 22.78 & 20.71 & 20.69 & 21.06 \\
\hline Crude fiber & 3.50 & 3.51 & 3.53 & 3.59 & 3.47 & 3.75 \\
\hline Ether extract & 3.74 & 3.82 & 3.78 & 3.81 & 3.61 & 3.44 \\
\hline Ash & 7.12 & 7.25 & 7.50 & 7.69 & 7.73 & 7.33 \\
\hline Nitrogen free extract & 54.60 & 54.53 & 53.94 & 55.87 & 56.29 & 56.42 \\
\hline
\end{tabular}

\section{Statistical analysis}

Data were statistically analyzed using general linear models procedure of SAS (SAS Institute Inc., 2006) as a factorial arrangement $(2 \times 2 \times 3)$, including PL, OA types and OA levels as the main and their combined effects. Means comparisons were performed using Duncan's multiple range test (5\%; Duncan, 1955).

\section{RESULTS AND DISCUSSION}

\section{Growth Performance}

As shown in Tables ( 2 and 3 ) birds fed RPL diets during all feeding periods and total period gained and consumed feed higher than those fed LPL diets with significant $(P \leq 0.05)$ differences during starter, grower and total periods (for $\mathrm{ADG}$ ) and grower, finisher and total periods (for ADFI). The gain improvement was reduced with the progress of birds' age and the corresponding values were 6.89, 5.40 and $1.18 \%$ during starter, grower and finisher periods, respectively. This might be due that younger chicks grow faster and are more sensitive to protein deficiency than the older ones. Besides, the metabolizable energy (ME) content was the same for all diets (3200 Kcal ME/ kg diet) which elucidate the reason that feed data did not reveal any changes during starter phase. The best values of FCR and CCR were recorded by RPL diets during starter $(P<0.05)$ and grower periods while during finisher 
$(P \leq 0.05)$ and total periods the best ratios were obtained by LPL diets. However, the best significant $(P \leq 0.05)$ CPCR values were achieved by LPL diets during all periods (Table 4, 5 and 6$)$. The increments in FCR, CPCR and CCR values might be due to that the chicks fed low CP diets consumed less feed and were grown slower. Controversial results have been documented on the effect of feeding low CP diet compared to the recommended CP diet for broilers. A Reduction in growth and an increase in FCR for birds fed low protein diets were reported (Ragab et al., 2012, and Si et al., 2004). On the other hand, Dehghani-Tafti and Jahanian (2016) reported that reducing dietary CP level by $2 \%$ did not adversely affect weight gain (during the starter and finisher periods) when the limiting amino acids were provided at sufficient quantities. In harmony with that, Azarnik et al. (2010) observed that dietary CP level could be reduced by $2 \%$ after the starter period without any detrimental influence on growth performance of broilers. Similarly, Kamran et al. (2011) studied the effect of reducing dietary CP by about 3\% on broilers performance during all growth periods and found no significant differences between protein levels. Results of dietary CP on broiler performance varied between researchers because of the differences in applied management and hygiene. Microflora-specific immunoglobulin secretion could affect growth which in turn reduce muscle protein deposition and affect body weight gain (BWG). Besides, bacteria in gut compete with the host for up-taking amino acids, thereby reducing nitrogen utilization (Furuse and Yokota, 1985). Also, these bacteria can ferment amino acids, producing toxic metabolites which can affect intestinal cell turnover and growth performance (Vander Klis and Jansman, 2002).

Table (1, b). Formulation and chemical analysis (calculated and determined) of broiler grower diets (4-5 wk).

\begin{tabular}{|c|c|c|c|c|c|c|}
\hline \multirow{2}{*}{$\begin{array}{l}\text { Diets (CP \%) / } \\
\text { Ingredients\% }\end{array}$} & \multicolumn{3}{|c|}{20 (Required protein level) } & \multicolumn{3}{|c|}{18 (Low protein level) } \\
\hline & & & & & & \\
\hline Yellow corn & 60.39 & 58.60 & 56.21 & 64.31 & 61.90 & 60.00 \\
\hline Soybean meal $44 \%$ & 26.00 & 23.81 & 23.49 & 26.00 & 25.07 & 24.00 \\
\hline Corn glu. meal $60 \%$ & 6.00 & 8.00 & 8.50 & 2.00 & 3.20 & 4.00 \\
\hline Veget.oil & 4.00 & 4.40 & 5.10 & 4.18 & 4.80 & 5.40 \\
\hline Limestone & 1.44 & 1.50 & 1.50 & 1.44 & 1.44 & 1.46 \\
\hline Di-Ca phosphate & 1.22 & 1.23 & 1.23 & 1.21 & 1.22 & 1.24 \\
\hline${ }^{1}$ Vit.+ min. premix & 0.30 & 0.30 & 0.30 & 0.30 & 0.30 & 0.30 \\
\hline $\mathrm{NaCl}$ & 0.40 & 0.40 & 0.40 & 0.40 & 0.40 & 0.40 \\
\hline DL- Methionine & 0.03 & 0.01 & 0.01 & 0.04 & 0.03 & 0.03 \\
\hline L-Lysine $\mathrm{HCl}$ & 0.12 & 0.15 & 0.16 & 0.02 & 0.04 & 0.07 \\
\hline Choline chloride & 0.10 & 0.10 & 0.10 & 0.10 & 0.10 & 0.10 \\
\hline${ }^{2}$ Organic acid level & 0 & 1.50 & 3.00 & 0 & 1.50 & 3.00 \\
\hline Total & 100 & 100 & 100 & 100 & 100 & 100 \\
\hline \multicolumn{7}{|l|}{ Calculated values $\%$} \\
\hline $\mathrm{ME}(\mathrm{Kcal} / \mathrm{Kg})$ & 3206 & 3210 & 3206 & 3201 & 3208 & 3207 \\
\hline Crude protein & 20.42 & 20.56 & 20.54 & 18.11 & 18.21 & 18.06 \\
\hline Lysine & 1.006 & 1.009 & 1.010 & 0.905 & 0.904 & 0.906 \\
\hline Methionine & 0.389 & 0.382 & 0.383 & 0.345 & 0.343 & 0.346 \\
\hline Meth+Cystine & 0.733 & 0.733 & 0.733 & 0.655 & 0.656 & 0.656 \\
\hline Calcium & 0.902 & 0.922 & 0.920 & 0.901 & 0.900 & 0.910 \\
\hline Available Phosphorus & 0.355 & 0.352 & 0.350 & 0.350 & 0.350 & 0.351 \\
\hline \multicolumn{7}{|l|}{ Determined values $\%$} \\
\hline Moisture & 8.05 & 8.05 & 8.44 & 8.11 & 8.19 & 8.30 \\
\hline Crude protein & 19.85 & 19.92 & 19.83 & 17.99 & 17.98 & 18.09 \\
\hline Crude fiber & 3.84 & 3.69 & 3.74 & 3.76 & 3.65 & 3.50 \\
\hline Ether extract & 3.49 & 3.92 & 3.63 & 3.73 & 3.67 & 3.52 \\
\hline Ash & 7.56 & 7.61 & 7.80 & 7.86 & 7.95 & 7.91 \\
\hline Nitrogen free extract & 57.21 & 56.81 & 56.56 & 58.55 & 58.56 & 58.68 \\
\hline
\end{tabular}

${ }^{I}$ Supplied per kilogram of diet: Vitamin A, $12000 \mathrm{IU}$; Vitamin D3, $2000 \mathrm{IU}$; Vitamin E, $10 \mathrm{mg}$; Vitamin K3, $2.0 \mathrm{mg}$; Thiamin, $1.0 \mathrm{mg}$; Riboflavin, $5.0 \mathrm{mg}$; Pyridoxine, $1.5 \mathrm{mg}$; Cyanocobalamin, $0.01 \mathrm{mg}$; Pantothenic acid, $10 \mathrm{mg}$; Nicotinic acid, $30 \mathrm{mg}$, Folic acid, $1.0 \mathrm{mg}$; Biotin, $0.05 \mathrm{mg}$; Choline chloride, $250 \mathrm{mg} ; \mathrm{Cu}, 10 \mathrm{mg} ; \mathrm{I}, 1.0 \mathrm{mg} ; \mathrm{Fe}, 30 \mathrm{mg} ; \mathrm{Zn}, 50 \mathrm{mg}$; $\mathrm{Mn}, 60 \mathrm{mg}$; Co, $0.1 \mathrm{mg}$; and $\mathrm{Se}, 0.1 \mathrm{mg} . \quad{ }^{2}$ Citric or fumaric acids 
Egyptian J. Nutrition and Feeds (2018)

Table (1, c). Formulation and chemical analysis (calculated and determined) of broiler finisher diets (the $6^{\text {th }}$ wk).

\begin{tabular}{|c|c|c|c|c|c|c|}
\hline \multirow{2}{*}{$\begin{array}{l}\text { Diets (CP \%) } \\
\text { Ingredients\% }\end{array}$} & \multicolumn{3}{|c|}{18 (Required protein level) } & \multicolumn{3}{|c|}{16 (Low protein level) } \\
\hline & & & & & & \\
\hline Yellow corn & 65.00 & 63.00 & 60.98 & 70.16 & 67.50 & 65.40 \\
\hline Soybean meal $44 \%$ & 26.38 & 24.88 & 23.35 & 23.00 & 23.00 & 22.10 \\
\hline Corn glu. meal $60 \%$ & 1.50 & 3.00 & 4.50 & - & 0.50 & 1.50 \\
\hline Veget.oil & 4.00 & 4.50 & 5.00 & 3.70 & 4.36 & 4.86 \\
\hline Limestone & 1.30 & 1.31 & 1.32 & 1.32 & 1.32 & 1.33 \\
\hline Di-Ca phosphate & 1.00 & 1.00 & 1.00 & 1.00 & 1.00 & 1.00 \\
\hline${ }^{1}$ Vit.+ min. premix & 0.30 & 0.30 & 0.30 & 0.30 & 0.30 & 0.30 \\
\hline $\mathrm{NaCl}$ & 0.40 & 0.40 & 0.40 & 0.40 & 0.40 & 0.40 \\
\hline DL- Methionine & 0.02 & 0.01 & 0.01 & 0.02 & 0.02 & 0.01 \\
\hline L-Lysine $\mathrm{HCl}$ & - & - & 0.04 & - & - & - \\
\hline Choline chloride & 0.10 & 0.10 & 0.10 & 0.10 & 0.10 & 0.10 \\
\hline${ }^{2}$ Organic acid level & 0 & 1.50 & 3.00 & 0 & 1.50 & 3.00 \\
\hline Total & 100 & 100 & 100 & 100 & 100 & 100 \\
\hline \multicolumn{7}{|l|}{ Calculated values\% } \\
\hline ME (Kcal/Kg) & 3202 & 3204 & 3206 & 3208 & 3207 & 3201 \\
\hline Crude protein & 18.07 & 18.17 & 18.29 & 16.08 & 16.16 & 16.18 \\
\hline Lysine & 0.894 & 0.864 & 0.869 & 0.801 & 0.800 & 0.779 \\
\hline Methionine & 0.323 & 0.322 & 0.331 & 0.288 & 0.291 & 0.287 \\
\hline Meth+Cystine & 0.630 & 0.633 & 0.646 & 0.566 & 0.569 & 0.567 \\
\hline Calcium & 0.804 & 0.803 & 0.802 & 0.803 & 0.803 & 0.802 \\
\hline Available Phosphorus & 0.312 & 0.308 & 0.305 & 0.305 & 0.304 & 0.301 \\
\hline \multicolumn{7}{|l|}{ Determined values $\%$} \\
\hline Moisture & 7.72 & 8.02 & 8.01 & 7.95 & 8.15 & 7.90 \\
\hline Crude protein & 17.89 & 17.92 & 17.87 & 15.96 & 15.75 & 15.85 \\
\hline Crude fiber & 3.75 & 3.53 & 3.55 & 3.83 & 3.58 & 3.47 \\
\hline Ether extract & 3.54 & 3.44 & 3.57 & 3.44 & 3.68 & 3.70 \\
\hline Ash & 6.12 & 5.97 & 5.90 & 7.83 & 7.80 & 7.98 \\
\hline Nitrogen free extract & 60.98 & 61.12 & 61.10 & 60.99 & 61.04 & 61.10 \\
\hline
\end{tabular}

${ }^{I}$ Supplied per kilogram of diet: Vitamin A, 12000 IU; Vitamin D3, 2000 IU; Vitamin E, 10 mg; Vitamin K3, 2.0 mg; Thiamin, $1.0 \mathrm{mg}$; Riboflavin, $5.0 \mathrm{mg}$; Pyridoxine, $1.5 \mathrm{mg}$; Cyanocobalamin, $0.01 \mathrm{mg}$; Pantothenic acid, $10 \mathrm{mg}$; Nicotinic acid, $30 \mathrm{mg}$, Folic acid, $1.0 \mathrm{mg}$; Biotin, $0.05 \mathrm{mg}$; Choline chloride, $250 \mathrm{mg}$; Cu, $10 \mathrm{mg}$;, $1.0 \mathrm{mg}$; Fe, $30 \mathrm{mg} ; \mathrm{Zn}, 50 \mathrm{mg}$; $\mathrm{Mn}, 60 \mathrm{mg}$; Co, $0.1 \mathrm{mg}$; and Se, $0.1 \mathrm{mg} . \quad{ }^{2}$ Citric or fumaric acids

No significant differences were noticed between the effects of CA and FUA diets on all birds' criteria. Conversely, there were significant differences $(P \leq 0.05)$ between organic acid levels $(\mathrm{OAL})$ for all birds' criteria (except for ADG during finisher period). Diet supplemented with 1.5\% OA increased ADG by $2.03 \%$ in comparison with $0 \%$ OA diet during the starter period but the data failed to show any significant differences. However, increasing OAL to $3 \%$ reduced gain significantly $(P \leq 0.05)$ compared with $1.5 \%$ during starter, grower and total periods in comparison with 0 and $1.5 \%$ OA diets. Birds fed $0 \%$ OA diet consumed significantly $(P \leq 0.05)$ higher feed and had the worst FCR, CPCR and CCR compared to those fed $1.5 \%$ or $3 \% \mathrm{OA}$ diets for all feeding periods. The best values for all criteria were obtained by $1.5 \%$ OA diets (Tables 4, 5 and 6). The improvement in the former criteria could be due to better utilization of nutrients in which birds fed diets supplemented with $1.5 \%$ OA consumed less feed and had a comparable gain. Ricke (2003) reported that increased BWG is probably due to the beneficial effect of organic acids in gut flora. The organic acids may have a bactericidal effect; it could affect the integrity of microbial cell membrane, cell macromolecules or interfere with the nutrient transport and energy metabolism. Additionally, the improvements in ADG and FCR by dietary OA may be, in part, due to the increase in villi height and increased absorptive surface area as reported by Mohammadagheri et al. (2016). Besides, these results agreed with Adil et al. (2010) who stated that broiler diet supplemented with OA improved BWG when compared to control diet. However, Hernandez et al. (2006) reported no significant effect of organic acid supplementation on broilers growth performance.

Significant $(P \leq 0.05)$ differences in ADG, ADFI (Tables 2 and 3), FCR, CPCR and CCR were observed as a result of the combined effects of dietary PL, OAT and OAL. Birds fed RPL+1.5\% CA diet had the highest significant $(P \leq 0.05)$ ADG value during starter and finisher periods while during grower and total periods, RPL $+1.5 \%$ FUA diet recorded the superior ADG compared with the other treatments. The lowest significant $(P \leq 0.05)$ ADFI values were noticed with RPL $+3 \%$ FUA diet (starter), LPL $+1.5 \%$ 
FUA diet (finisher) and LPL+3\% CA diet (grower and total period). In most feeding periods, the best values for FCR and CCR were recorded with RPL+1.5\% FUA diet (Table 4 and 6); however, the worst values were observed with RPL or LPL $+0 \%$ OA diets. Treatments effect on CPCR was inconsistent and the best values were recorded with LPL $+1.5 \% \mathrm{CA}$ diet (grower and total periods), LPL $+1.5 \%$ FUA diet (starter) or LPL $+3 \%$ FUA diet (finisher). Partially, supplementation of CA or FUA to LPL diet significantly $(P \leq 0.05)$ improved FCR, CPCR and CCR during starter period (Table 4, 5 and 6). Similar results were observed by Dehghani-Tafti and Jahanian (2016) who reported that dietary supplementation of $2.5 \mathrm{~g} / \mathrm{kg} \mathrm{CA}$ with high and medium CP broiler diets increased ADG during starter and finisher periods resulting in improved FCR values. Also, Mohammadagheri et al. (2016) concluded that supplemented CA to broiler diet decreased feed intake which agreed with the reported data. In another trial, Adil et al. (2011a) noticed that 2-3\% fumaric acid decreased cumulative feed intake compared to the control group. However, 3\% fumaric acid in broiler diet significantly improved BWG and FCR with no effect on total feed intake (Adil et al., 2010, 2011b). The authors attributed the reduction in the feed intake to the strong taste associated with the organic acids which would have decreased the palatability of the feed, thereby reducing feed intake. Also, Nourmohammadi et al. (2010) reported positive effects from the utilization of $3 \% \mathrm{CA}$ in broiler diets. They concluded that $\mathrm{CA}$ provided suitable $\mathrm{pH}$ in the gut for proteolytic enzymes activity and increased feed digestion by a reduction in the gut microflora. Moreover, the downfall in $\mathrm{pH}$ reduced the gut digested food transmission speed and this may result in a reduction in FI for birds fed diets containing 6\% CA. Similarly, Ragab et al. (2012) observed that chicks fed diets containing the recommended level of $\mathrm{CP}+2 \%$ lactic or $\mathrm{CA}$ had the highest $\mathrm{BWG}$ while those fed diet low in $\mathrm{CP}$ (by $2 \%$ ) without OA had the lowest BWG with no significant differences. The authors concluded that neither the type of addition nor the interaction between types of addition with the level of CP had any significant effect on BWG. Additionally, Ghazalah et al. (2011) reported that broiler chicks fed diets supplemented with CA (1-3\%) or FUA (0.5-1.5\%) increased BWG significantly.

Table (2). Effects of crude protein levels, organic acids (types and levels) on gain and mortality rate of broiler chicks.

\begin{tabular}{|c|c|c|c|c|c|}
\hline \multirow{3}{*}{ Treatment } & \multicolumn{4}{|c|}{ Average daily gain $(\mathrm{g} / \mathrm{b} / \mathrm{d})$} & \multirow{3}{*}{$\begin{array}{c}\text { Mortality } \\
\text { rate }\end{array}$} \\
\hline & \multicolumn{4}{|c|}{ Periods, weeks } & \\
\hline & Starter $(0-3)$ & Grower (4-5) & Finisher $\left(6^{\text {th }}\right)$ & Total (0-6) & \\
\hline \multicolumn{6}{|l|}{ Main Effects } \\
\hline${ }^{1} \mathrm{PL} \quad \mathrm{R}$ & $39.70^{\mathrm{a}} \pm 0.29$ & $62.86^{\mathrm{a}} \pm 0.72$ & $58.38 \pm 1.11$ & $50.64^{\mathrm{a}} \pm 0.38$ & 3.47 \\
\hline $\mathrm{L}$ & $37.14^{\mathrm{b}} \pm 0.35$ & $59.64^{\mathrm{b}} \pm 0.73$ & $57.70 \pm 1.09$ & $48.10^{\mathrm{b}} \pm 0.41$ & 2.78 \\
\hline P-value & $<.0001$ & 0.0012 & 0.1738 & $<.0001$ & 0.7753 \\
\hline${ }^{2} \mathrm{OAT} \quad \mathrm{CA}$ & $38.58 \pm 0.34$ & $60.77 \pm 0.73$ & $58.30 \pm 1.08$ & $49.33 \pm 0.41$ & 2.78 \\
\hline FUA & $38.27 \pm 0.33$ & $61.62 \pm 0.74$ & $57.75 \pm 1.11$ & $49.31 \pm 0.41$ & 3.47 \\
\hline P-value & 0.3940 & 0.2818 & 0.6105 & 0.9105 & 0.7753 \\
\hline${ }^{3} \mathrm{OAL} \% \quad 0$ & $38.40^{\mathrm{ab}} \pm 0.30$ & $62.44^{\mathrm{a}} \pm 0.68$ & $58.30 \pm 1.07$ & $49.88^{\mathrm{a}} \pm 0.36$ & 6.25 \\
\hline 1.5 & $39.18^{\mathrm{a}} \pm 0.51$ & $61.58^{\mathrm{a}} \pm 1.14$ & $57.76 \pm 1.78$ & $49.67^{\mathrm{a}} \pm 0.67$ & 0 \\
\hline 3.0 & $37.71^{\mathrm{b}} \pm 0.52$ & $58.51^{\mathrm{b}} \pm 1.03$ & $57.80 \pm 1.37$ & $47.98^{\mathrm{b}} \pm 0.58$ & 3.12 \\
\hline P-value & 0.0663 & 0.0041 & 0.9890 & 0.0107 & 0.1272 \\
\hline Combined Effects & & & & & \\
\hline $\mathrm{RPL} \times \mathrm{OA} 0$ & $40.04^{\mathrm{ab}} \pm 0.48$ & $64.02^{\mathrm{ab}} \pm 1.29$ & $55.81^{\mathrm{ab}} \pm 2.38$ & $50.94^{\mathrm{ab}} \pm 0.69$ & 8.30 \\
\hline $\mathrm{RPL} \times \mathrm{CA} 1.5$ & $41.76^{\mathrm{a}} \pm 0.67$ & $58.42^{b c} \pm 2.14$ & $64.54^{\mathrm{a}} \pm 2.97$ & $51.22^{\mathrm{ab}} \pm 1.00$ & 0 \\
\hline $\mathrm{RPL} \times \mathrm{CA} 3.0$ & $37.59^{b c} \pm 1.03$ & $62.65^{\mathrm{abc}} \pm 1.67$ & $60.91^{\mathrm{ab}} \pm 2.94$ & $49.83^{\mathrm{ab}} \pm 1.06$ & 4.17 \\
\hline $\mathrm{RPL} \times \mathrm{OA} 0$ & $40.04^{\mathrm{ab}} \pm 0.48$ & $64.02^{\mathrm{ab}} \pm 1.29$ & $55.81^{\mathrm{ab}} \pm 2.38$ & $50.94^{\mathrm{ab}} \pm 0.69$ & 8.30 \\
\hline RPL $\times$ FUA 1.5 & $40.39^{\mathrm{a}} \pm 0.98$ & $67.32^{\mathrm{a}} \pm 2.34$ & $59.24^{\mathrm{ab}} \pm 2.57$ & $52.51^{\mathrm{a}} \pm 1.15$ & 0 \\
\hline RPL $\times$ FUA 3.0 & $37.72^{\mathrm{bc}} \pm 0.87$ & $59.08^{b c} \pm 2.14$ & $57.99^{\mathrm{ab}} \pm 3.13$ & $48.22^{\mathrm{bc}} \pm 1.13$ & 0 \\
\hline $\mathrm{LPL} \times \mathrm{OA} 0$ & $36.76^{\mathrm{c}} \pm 0.61$ & $61.05^{\mathrm{bc}} \pm 1.38$ & $60.40^{\mathrm{ab}} \pm 1.94$ & $48.98^{\mathrm{b}} \pm 0.71$ & 4.17 \\
\hline $\mathrm{LPL} \times \mathrm{CA} 1.5$ & $37.79^{b c} \pm 0.98$ & $63.09^{\mathrm{abc}} \pm 1.83$ & $56.00^{\mathrm{ab}} \pm 3.62$ & $49.26^{\mathrm{b}} \pm 1.33$ & 0 \\
\hline $\mathrm{LPL} \times \mathrm{CA} 3.0$ & $37.88^{b c} \pm 1.24$ & $52.74^{\mathrm{d}} \pm 2.22$ & $52.54^{\mathrm{b}} \pm 2.20$ & $45.28^{\mathrm{d}} \pm 1.33$ & 0 \\
\hline $\mathrm{LPL} \times \mathrm{OA} 0$ & $36.76^{c} \pm 0.61$ & $61.05^{\mathrm{bc}} \pm 1.38$ & $60.40^{\mathrm{ab}} \pm 1.94$ & $48.98^{\mathrm{b}} \pm 0.71$ & 4.17 \\
\hline LPL $\times$ FUA 1.5 & $36.83^{\mathrm{c}} \pm 1.11$ & $57.59^{\mathrm{cd}} \pm 2.33$ & $51.91^{\mathrm{b}} \pm 4.39$ & $45.84^{\mathrm{cd}} \pm 1.42$ & 0 \\
\hline LPL $\times$ FUA 3.0 & $37.64^{\mathrm{c}} \pm 1.04$ & $59.63^{\mathrm{bc}} \pm 1.67$ & $59.95^{\mathrm{ab}} \pm 2.40$ & $48.63^{b c} \pm 0.90$ & 8.30 \\
\hline SEM & \pm 0.24 & \pm 0.52 & \pm 0.78 & \pm 0.29 & \pm 1.16 \\
\hline P-value & $<.0001$ & $<.0001$ & 0.0840 & $<.0001$ & 0.6828 \\
\hline
\end{tabular}

Means with no common superscripts within the column of each classification (PL, OAL or combined effects) are significantly $(P \leq 0.05)$ different. ${ }^{I}$ Protein Level $\left(R\right.$, required, RPL or L, low, LPL). ${ }^{2}$ Organic Acid Type, CA: Citric Acid; FUA: Fumaric Acid ${ }^{3}$ Organic Acid Level. 
Egyptian J. Nutrition and Feeds (2018)

Table (3). Effects of crude protein levels, organic acids (types and levels) on feed intake of broiler chicks.

\begin{tabular}{|c|c|c|c|c|}
\hline \multirow{3}{*}{ Treatment } & \multicolumn{4}{|c|}{ Average daily feed intake $(\mathrm{g} / \mathrm{b} / \mathrm{d})$} \\
\hline & \multicolumn{4}{|c|}{ Periods, weeks } \\
\hline & Starter $(0-3)$ & Grower (4-5) & Finisher $\left(6^{\text {th }}\right)$ & Total (0-6) \\
\hline \multicolumn{5}{|l|}{ Main Effects } \\
\hline${ }^{1} \mathrm{PL} \quad \mathrm{R}$ & $45.84 \pm 0.44$ & $105.10^{\mathrm{a}} \pm 1.99$ & $116.47^{\mathrm{a}} \pm 3.19$ & $77.36^{\mathrm{a}} \pm 1.28$ \\
\hline $\mathrm{L}$ & $45.54 \pm 0.37$ & $100.94^{\mathrm{b}} \pm 1.67$ & $103 / 06^{\mathrm{b}} \pm 1.77$ & $73.59^{\mathrm{b}} \pm 0.80$ \\
\hline P-value & 0.8301 & 0.0727 & 0.0004 & 0.0035 \\
\hline${ }^{2} \mathrm{OAT} \quad \mathrm{CA}$ & $45.73 \pm 0.40$ & $104.14 \pm 2.01$ & $110.55 \pm 2.86$ & $75.70 \pm 1.15$ \\
\hline FUA & $45.65 \pm 0.42$ & $101.90 \pm 1.72$ & $108.99 \pm 2.99$ & $75.25 \pm 1.12$ \\
\hline P-value & 0.8425 & 0.1192 & 0.4649 & 0.5397 \\
\hline${ }^{3} \mathrm{OAL} \% \quad 0$ & $46.96^{\mathrm{a}} \pm 0.29$ & $109.17^{\mathrm{a}} \pm 1.28$ & $117.51^{\mathrm{a}} \pm 2.89$ & $79.45^{\mathrm{a}} \pm 0.86$ \\
\hline 1.5 & $44.55^{\mathrm{b}} \pm 0.39$ & $98.47^{\mathrm{b}} \pm 1.87$ & $103.37^{\mathrm{b}} \pm 3.49$ & $72.33^{\mathrm{b}} \pm 1.07$ \\
\hline 3.0 & $44.30^{\mathrm{b}} \pm 0.55$ & $95.25^{\mathrm{b}} \pm 2.30$ & $100.67^{\mathrm{b}} \pm 1.65$ & $70.68^{\mathrm{b}} \pm 0.83$ \\
\hline P-value & $<.0001$ & $<.0001$ & $<.0001$ & $<.0001$ \\
\hline Combined Effects & & & & \\
\hline $\mathrm{RPL} \times \mathrm{OA} 0$ & $47.39^{a} \pm 0.55$ & $112.29^{\mathrm{a}} \pm 2.41$ & $127.91^{\mathrm{a}} \pm 4.50$ & $82.45^{\mathrm{a}} \pm 1.54$ \\
\hline $\mathrm{RPL} \times \mathrm{CA} 1.5$ & $45.34^{\mathrm{abc}} \pm 0.91$ & $93.48 c^{\mathrm{d}} \pm 2.38$ & $115.15^{\mathrm{ab}} \pm 8.91$ & $73.02^{\text {bcd }} \pm 2.39$ \\
\hline $\mathrm{RPL} \times \mathrm{CA} 3.0$ & $43.82^{\mathrm{bc}} \pm 1.54$ & $96.98 b^{c} \pm 2.39$ & $100.92^{\mathrm{bc}} \pm 1.55$ & $71.06^{\mathrm{bcd}} \pm 1.47$ \\
\hline $\mathrm{RPL} \times \mathrm{OA} 0$ & $47.39^{\mathrm{a}} \pm 055$ & $112.29^{\mathrm{a}} \pm 2.41$ & $127.91^{\mathrm{a}} \pm 4.50$ & $82.45^{\mathrm{a}} \pm 1.54$ \\
\hline RPL $\times$ FUA 1.5 & $44.51^{\mathrm{bc}} \pm 0.86$ & $101.85^{\mathrm{bc}} \pm 5.27$ & $107.10^{\mathrm{bc}} \pm 2.31$ & $74.06^{\mathrm{bc}} \pm 2.54$ \\
\hline RPL $\times$ FUA 3.0 & $43.47^{c} \pm 0.17$ & $99.27 b^{c} \pm 6.49$ & $96.97^{c} \pm 5.26$ & $70.98^{\mathrm{bcd}} \pm 2.24$ \\
\hline $\mathrm{LPL} \times \mathrm{OA} 0$ & $46.52^{\mathrm{ab}} \pm 0.64$ & $106.05^{\mathrm{ab}} \pm 2.30$ & $107.12^{\mathrm{bc}} \pm 3.64$ & $76.46^{\mathrm{b}} \pm 0.90$ \\
\hline $\mathrm{LPL} \times \mathrm{CA} 1.5$ & $44.50 b^{c} \pm 0.83$ & $101.55^{\mathrm{bc}} \pm 1.49$ & $97.09^{c} \pm 0.88$ & $72.28^{\mathrm{bcd}} \pm 1.03$ \\
\hline $\mathrm{LPL} \times \mathrm{CA} 3.0$ & $44.34 b^{c} \pm 0.17$ & $86.47^{\mathrm{d}} \pm 3.41$ & $101.16^{\mathrm{bc}} \pm 0.18$ & $67.85^{\mathrm{d}} \pm 1.04$ \\
\hline $\mathrm{LPL} \times \mathrm{OA} 0$ & $46.52^{\mathrm{ab}} \pm 0.64$ & $106.05^{\mathrm{ab}} \pm 2.30$ & $107.12^{b c} \pm 3.64$ & $76.46^{\mathrm{b}} \pm 0.90$ \\
\hline LPL $\times$ FUA 1.5 & $43.84 b^{c} \pm 0.72$ & $97.01^{b c} \pm 4.16$ & $94.15^{\mathrm{c}} \pm 6.60$ & $69.95^{\mathrm{cd}} \pm 2.71$ \\
\hline LPL $\times$ FUA 3.0 & $45.59^{\mathrm{abc}} \pm 1.68$ & $98.28^{b c} \pm 1.97$ & $103.65^{\mathrm{bc}} \pm 4.26$ & $72.83^{\mathrm{bcd}} \pm 0.68$ \\
\hline SEM & \pm 0.29 & \pm 1.32 & \pm 2.05 & \pm 0.79 \\
\hline $\mathrm{P}$-value & 0.0029 & $<.0001$ & $<.0001$ & $<.0001$ \\
\hline
\end{tabular}

Means with no common superscripts within the column of each classification (PL, OAL or combined effects) are significantly $(P \leq 0.05)$ different. $\quad{ }^{1}$ Protein Level $\left(R\right.$, required, RPL or L, low, LPL) ${ }^{2}$ Organic Acid Type, CA: Citric Acid; FUA: Fumaric Acid ${ }^{3}$ Organic Acid Level.

\section{Mortality rate}

No significant effect on mortality rate either by PL, OAT or OAL main or combined effects during the experimental periods (Table 2 ). Total percentage of birds' mortality was $3.12 \%$ during the experimental period (6wk) which occurred mostly during finisher period. The highest mortality $(8.30 \%)$ was recorded with RPL+0\% OA or LPL+3\% FUA diets. Experimental treatments did not elevate mortality percent and did not have an exact connection with the mortality. No health problems and no great differences in MR were observed when broiler chicks fed diets supplemented with OA (Brzoska et al., 2013; Ghazalah et al., 2011). Furthermore, Islam et al. (2008) showed that birds fed diets supplemented with different levels of FUA up to $7.5 \%$ had MR averaged from 0 to $4 \%$. Similarly, Ragab et al. (2012) stated that low protein diet supplemented with OA (lactic or and CA) had no significant effect on mortality rate.

\section{Carcass characteristics}

Crude protein levels significantly affected $(P \leq 0.05)$ all carcass characteristics \% except for giblets (Table 7 and 8). Chicks fed RPL diet had a higher percentage of dressing, meat, and meat: bone or fat ratios and the lowest percentage of inedible parts, bone and abdominal fat. These results conflicted with Kamran et al. (2011) and Azarnik et al. (2010) who reported that carcass characteristics were not influenced by dietary CP levels. However, Dehghani-Tafti and Jahanian (2016) recorded that carcass yield and liver \% were decreased by reducing dietary CP level. Also, Huwaida et al. (2013) found that high protein level $(23 \%)$ significantly increased all carcass traits compared with $21 \%$ protein level. In the present study, the effect of CP level on abdominal fat was in agreement with Dehghani-Tafti and Jahanian (2016) who concluded that chicks fed low CP diets resulted in a more fat deposition in the carcass than 
medium or high CP diets. This may be due to that protein biosynthesis throughout the body was suppressed (Leeson and Summers, 2001). The significant effect of CP levels on meat \% agreed with Widyaratne and Drew (2011) who stated that breast meat yield decreased with lowering CP diets. On the contrary, Azarnik et al. (2010) showed that protein level had no significant effect on breast muscle or meat yield.

Table (4). Effects of crude protein levels and organic acids (types and levels) on feed conversion ratio of broiler chicks.

\begin{tabular}{|c|c|c|c|c|}
\hline \multirow{3}{*}{ Treatment } & \multicolumn{4}{|c|}{ Feed conversion ratio (g feed/g gain) } \\
\hline & \multicolumn{4}{|c|}{ Periods, weeks } \\
\hline & Starter (0-3) & Grower (4-5) & Finisher $\left(6^{\text {th }}\right)$ & Total $(0-6)$ \\
\hline \multicolumn{5}{|l|}{ Main effects } \\
\hline${ }^{1} \mathrm{PL} \quad \mathrm{R}$ & $1.16^{\mathrm{b}} \pm 0.01$ & $1.68 \pm 0.04$ & $2.06^{\mathrm{a}} \pm 0.09$ & $1.54 \pm 0.03$ \\
\hline $\mathrm{L}$ & $1.23^{\mathrm{a}} \pm 0.01$ & $1.70 \pm 0.02$ & $1,80^{\mathrm{b}} \pm 0.04$ & $1.53 \pm 0.01$ \\
\hline P-value & $<.0001$ & 0.3226 & 0.0894 & 0.4843 \\
\hline${ }^{2} \mathrm{OAT} \quad \mathrm{CA}$ & $1.19 \pm 0.01$ & $1.68 \pm 0.03$ & $1.93 \pm 0.07$ & $1.53 \pm 0.02$ \\
\hline FUA & $1.20 \pm 0.01$ & $1.70 \pm 0.03$ & $1.92 \pm 0.08$ & $1.54 \pm 0.02$ \\
\hline $\mathrm{P}$-value & 0.7036 & 0.4391 & 0.8244 & 0.5941 \\
\hline${ }^{3} \mathrm{OAL} \% \quad 0$ & $1.23^{\mathrm{a}} \pm 0.01$ & $1.76^{\mathrm{a}} \pm 0.03$ & $2.07^{\mathrm{a}} \pm 0.09$ & $1.60^{\mathrm{a}} \pm 0.02$ \\
\hline 1.5 & $1.14^{\mathrm{c}} \pm 0.02$ & $1.60^{\mathrm{b}} \pm 0.04$ & $1.80^{\mathrm{b}} \pm 0.05$ & $1.46^{\mathrm{b}} \pm 0.02$ \\
\hline 3.0 & $1.18^{\mathrm{b}} \pm 0.02$ & $1.64^{\mathrm{b}} \pm 0.03$ & $1.76^{\mathrm{b}} \pm 0.06$ & $1.48^{\mathrm{b}} \pm 0.02$ \\
\hline P-value & $<.0001$ & 0.0029 & 0.0036 & $<.0001$ \\
\hline \multicolumn{5}{|l|}{ Combined effects } \\
\hline $\mathrm{RPL} \times \mathrm{OA} 0$ & $1.18^{\mathrm{b}} \pm 0.01$ & $1.78^{\mathrm{a}} \pm 0.08$ & $2.36^{\mathrm{a}} \pm 0.18$ & $1.64^{\mathrm{a}} \pm 0.06$ \\
\hline RPL $\times$ CA 1.5 & $1.11^{\mathrm{cd}} \pm 0.03$ & $1.56^{\mathrm{ab}} \pm 0.08$ & $1.83^{\mathrm{b}} \pm 0.11$ & $1.42^{\mathrm{b}} \pm 0.02$ \\
\hline $\mathrm{RPL} \times \mathrm{CA} 3.0$ & $1.17^{\mathrm{bc}} \pm 0.03$ & $1.55^{\mathrm{ab}} \pm 0.03$ & $1.66^{\mathrm{b}} \pm 0.07$ & $1.43^{\mathrm{b}} \pm 0.01$ \\
\hline $\mathrm{RPL} \times \mathrm{OA} 0$ & $1.18^{\mathrm{b}} \pm 0.01$ & $1.78^{\mathrm{a}} \pm 0.08$ & $2.36^{\mathrm{a}} \pm 0.18$ & $1.64^{\mathrm{a}} \pm 0.06$ \\
\hline RPL $\times$ FUA 1.5 & $1.10^{\mathrm{d}} \pm 0.01$ & $1.52^{\mathrm{b}} \pm 0.04$ & $1.82^{\mathrm{b}} \pm 0.12$ & $1.41^{\mathrm{b}} \pm 0.01$ \\
\hline RPL $\times$ FUA 3.0 & $1.15^{\mathrm{bcd}} \pm 0.02$ & $1.68^{\mathrm{ab}} \pm 0.02$ & $1.67^{\mathrm{b}} \pm 0.06$ & $1.47^{\mathrm{b}} \pm 0.01$ \\
\hline $\mathrm{LPL} \times \mathrm{OA} 0 \mathrm{LPL} \times \mathrm{CA}$ & $1.27^{\mathrm{a}} \pm 0.02$ & $1.74^{\mathrm{ab}} \pm 0.05$ & $1.78^{\mathrm{b}} \pm 0.08$ & $1.56^{\mathrm{ab}} \pm 0.02$ \\
\hline 1.5 & $1.18^{\mathrm{b}} \pm 0.02$ & $1.61^{\mathrm{ab}} \pm 0.02$ & $1.75^{\mathrm{b}} \pm 0.11$ & $1.47^{\mathrm{b}} \pm 0.01$ \\
\hline $\mathrm{LPL} \times \mathrm{CA} 3.0$ & $1.17^{\mathrm{bc}} \pm 0.03$ & $1.65^{\mathrm{ab}} \pm 0.09$ & $1.94^{\mathrm{ab}} \pm 0.11$ & $1.50^{\mathrm{ab}} \pm 0.06$ \\
\hline $\mathrm{LPL} \times \mathrm{OA} 0$ & $1.27^{\mathrm{a}} \pm 0.02$ & $1.74^{\mathrm{ab}} \pm 0.05$ & $1.78^{\mathrm{b}} \pm 0.08$ & $1.56^{\mathrm{ab}} \pm 0.02$ \\
\hline LPL $\times$ FUA 1.5 & $1.19^{\mathrm{b}} \pm 0.01$ & $1.71^{\mathrm{ab}} \pm 0.11$ & $1.82^{\mathrm{b}} \pm 0.12$ & $1.53^{\mathrm{ab}} \pm 0.05$ \\
\hline LPL $\times$ FUA 3.0 & $1.21^{\mathrm{ab}} \pm 0.04$ & $1.66^{\mathrm{ab}} \pm 0.07$ & $1.75^{\mathrm{b}} \pm 0.16$ & $1.50^{\mathrm{ab}} \pm 0.04$ \\
\hline SEM & \pm 0.01 & \pm 0.02 & $\pm 0.05 \pm$ & \pm 0.02 \\
\hline $\mathrm{P}$-value & $<.0001$ & 0.1020 & 0.0013 & 0.0028 \\
\hline
\end{tabular}

Means with no common superscripts within the column of each classification (PL, OAL or combined effects) are significantly $(P \leq 0.05)$ different. ${ }^{1}$ Protein Level (Required, RPL or Low, LPL) ${ }^{2}$ Organic Acid Type, CA: Citric Acid; FUA: Fumaric Acid ${ }^{3}$ Organic Acid Level. (0, $\left.1.5 \& 3 \%\right)$

Organic acid types had no significant effect on carcass criteria; however, OAL significantly $(P \leq 0.05)$ affected all carcass characteristics except for giblets. Diets with $1.5 \%$ OA achieved the highest $(P \leq 0.05)$ percentages of dressing and meat: fat ratio and the lowest inedible parts and abdominal fat followed by diets supplemented with 3 and 0\% OA. Similarly, Ahsan-ul-Haq et al. (2014) concluded that relative breast meat and giblet weight of broilers were not significantly affected while dressing percentage was significantly improved and abdominal fat weight was reduced with increasing CA $(0.5,1.0$ and $1.5 \%)$ in the diet. On the contrary, Brzoska et al. (2013) found that chicks fed CA at 3,6 and $9 \mathrm{~g} / \mathrm{kg}$ of diet had no significant effect on carcass characteristics. Additionally, slaughter characteristics of broiler chickens did not differ significantly as affected by various organic acids (butyric, FUA and lactic acid at 2 and 3\% of the diet; Adil et al., 2011b). Also, Nourmohammadi et al. (2010) showed that 3 or 6\% of CA supplemented to broiler diet had no significant effect on abdominal fat weight.

Supplementation of CA or FUA to RPL and LPL diets significantly $(P \leq 0.05)$ affected all carcass characteristics \%. Diets of RPL or LPL $+1.5 \%$ CA or FUA and RPL $+3 \%$ CA decreased $(P \leq 0.05)$ the inedible parts percentages compared to RPL or LPL+0\% OA. Dressing percentages were numerically increased with RPL or LPL+1.5 or $3 \%$ CA or FUA and the differences were significant when compared 
with LPL+0\% OA. Chicks fed RPL+0\% OA diet had the highest meat \% and M: B ratio. Conversely, the lowest significant abdominal fat, the highest giblets $\%$ and $\mathrm{M}$ : F ratio were recorded for chicks fed RPL $+1.5 \% \mathrm{CA}$ in comparison with both protein levels without OA (Table 7 and 8). This was in harmony with Dehghani-Tafti and Jahanian (2016) who reported that supplementation of CA ( $2.5 \mathrm{~g} / \mathrm{kg}$ diet) with different CP levels increased carcass yield but there was no effect on abdominal fat content. They concluded that the effect of OA supplementation was more pronounced in medium and high $\mathrm{CP}$ diets, representing that OA could decrease dietary CP. However, Ragab et al. (2012) found that neither type of addition ( $2 \%$ lactic or CA) nor the interaction between types and levels of CP had any significant effect on slaughter parameters.

Table (5). Effects of crude protein levels and organic acids (types and levels) on crude protein conversion ratio of broiler chicks.

\begin{tabular}{|c|c|c|c|c|}
\hline \multirow{3}{*}{ Treatment } & \multicolumn{4}{|c|}{ Crude protein conversion ratio (g CP/g gain) } \\
\hline & \multicolumn{4}{|c|}{ Periods, weeks } \\
\hline & Starter $(0-3)$ & Grower (4-5) & Finisher $\left(6^{\text {th }}\right)$ & Total (0-6) \\
\hline \multicolumn{5}{|l|}{ Main effects } \\
\hline${ }^{1} \mathrm{PL} \quad \mathrm{R}$ & $0.264^{\mathrm{a}} \pm 0.002$ & $0.333^{\mathrm{a}} \pm 0.007$ & $0.368^{\mathrm{a}} \pm 0.016$ & $0.311^{\mathrm{a}} \pm 0.006$ \\
\hline & $0.255^{\mathrm{b}} \pm 0.002$ & $0.306^{\mathrm{b}} \pm 0.004$ & $0.286^{\mathrm{b}} \pm 0.007$ & $0.281^{\mathrm{b}} \pm 0.002$ \\
\hline P-value & 0.0013 & 0.0085 & 0.0002 & $<.0001$ \\
\hline${ }^{2} \mathrm{OAT} \quad \mathrm{CA}$ & $0.260 \pm 0.003$ & $0.318 \pm 0.007$ & $0.328 \pm 0.015$ & $0.295 \pm 0.006$ \\
\hline FUA & $0.260 \pm 0.002$ & $0.321 \pm 0.006$ & $0.325 \pm 0.015$ & $0.297 \pm 0.005$ \\
\hline P-value & 0.7747 & 0.5523 & 0.7595 & 0.7226 \\
\hline${ }^{3} \mathrm{OAL} \% \quad 0$ & $0.267^{\mathrm{a}} \pm 0.002$ & $0.333^{\mathrm{a}} \pm 0.007$ & $0.354^{\mathrm{a}} \pm 0.018$ & $0.309^{\mathrm{a}} \pm 0.006$ \\
\hline 1.5 & $0.248^{\mathrm{c}} \pm 0.003$ & $0.302^{\mathrm{b}} \pm 0.007$ & $0.304^{\mathrm{b}} \pm 0.012$ & $0.281^{\mathrm{b}} \pm 0.003$ \\
\hline 3.0 & $0.258^{\mathrm{b}} \pm 0.004$ & $0.310^{\mathrm{b}} \pm 0.006$ & $0.295^{\mathrm{b}} 0.009$ & $0.286^{\mathrm{b}} \pm 0.004$ \\
\hline $\mathrm{P}$-value & $<.0001$ & 0.0041 & 0.0023 & $<.0001$ \\
\hline Combined effects & & & & \\
\hline $\mathrm{RPL} \times \mathrm{OA} 0$ & $0.271^{\mathrm{a}} \pm 0.002$ & $0.354^{\mathrm{a}} \pm 0.016$ & $0.423^{\mathrm{a}} \pm 0.031$ & $0.331^{\mathrm{a}} \pm 0.011$ \\
\hline $\mathrm{RPL} \times \mathrm{CA} 1.5$ & $0.251^{\mathrm{bc}} \pm 0.008$ & $0.311^{\mathrm{ab}} \pm 0.020$ & $0.327^{\mathrm{b}} \pm 0.025$ & $0.289^{\mathrm{b}} \pm 0.006$ \\
\hline $\mathrm{RPL} \times \mathrm{CA} 3.0$ & $0.266^{\mathrm{ab}} \pm 0.005$ & $0.309^{\mathrm{ab}} \pm 0.008$ & $0.295^{\mathrm{b}} \pm 0.007$ & $0.290^{\mathrm{b}} \pm 0.001$ \\
\hline $\mathrm{RPL} \times \mathrm{OA} 0$ & $0.271^{\mathrm{a}} \pm 0.002$ & $0.354^{\mathrm{a}} \pm 0.016$ & $0.423^{\mathrm{a}} \pm 0.031$ & $0.331^{\mathrm{a}} \pm 0.011$ \\
\hline RPL $\times$ FUA 1.5 & $0.251^{\mathrm{bc}} \pm 0.002$ & $0.300^{\mathrm{b}} \pm 0.004$ & $0.327^{\mathrm{b}} \pm 0.023$ & $0.286^{\mathrm{b}} \pm 0.003$ \\
\hline RPL $\times$ FUA 3.0 & $0.263^{\mathrm{ab}} \pm 0.007$ & $0.331^{\mathrm{ab}} \pm 0.004$ & $0.301^{\mathrm{b}} \pm 0.015$ & $0.298^{\mathrm{b}} \pm 0.003$ \\
\hline LPL $\times$ OA 0 LPLx & $0.262^{\mathrm{ab}} \pm 0.003$ & $0.313^{\mathrm{ab}} \pm 0.009$ & $0.285^{\mathrm{b}} \pm 0.015$ & $0.286^{\mathrm{b}} \pm 0.004$ \\
\hline CA 1.5 & $0.246^{\mathrm{c}} \pm 0.006$ & $0.288^{\mathrm{b}} \pm 0.006$ & $0.277^{\mathrm{b}} \pm 0.017$ & $0.270^{\mathrm{b}} \pm 0.003$ \\
\hline $\mathrm{LPL} \times \mathrm{CA} 3.0$ & $0.246^{\mathrm{c}} \pm 0.009$ & $0.300^{\mathrm{b}} \pm 0.012$ & $0.313^{\mathrm{b}} \pm 0.022$ & $0.280^{\mathrm{b}} \pm 0.011$ \\
\hline $\mathrm{LPL} \times \mathrm{OA} 0$ & $0.262^{\mathrm{ab}} \pm 0.003$ & $0.313^{\mathrm{ab}} \pm 0.009$ & $0.285^{\mathrm{b}} \pm 0.015$ & $0.286^{\mathrm{b}} \pm 0.004$ \\
\hline LPL $\times$ FUA 1.5 & $0.244^{\mathrm{c}} \pm 0.004$ & $0.308^{\mathrm{ab}} \pm 0.012$ & $0.285^{\mathrm{b}} \pm 0.021$ & $0.279^{\mathrm{b}} \pm 0.008$ \\
\hline LPL $\times$ FUA 3.0 & $0.255^{\mathrm{bc}} \pm 0.007$ & $0.299^{\mathrm{b}} \pm 0.012$ & $0.271^{\mathrm{b}} \pm 0.022$ & $0.276^{\mathrm{b}} \pm 0.007$ \\
\hline SEM & \pm 0.002 & \pm 0.005 & \pm 0.011 & \pm 0.004 \\
\hline P-value & 0.0002 & 0.0106 & $<.0001$ & $<.0001$ \\
\hline
\end{tabular}

Means with no common superscripts within the column of each classification (PL, OAL or combined effects) are significantly $(P \leq 0.05)$ different. ${ }^{1}$ Protein Level (Required, RPL or Low, LPL) ${ }^{2}$ Organic Acid Type, CA: Citric Acid; FUA: Fumaric Acid ${ }^{3}$ Organic Acid Level.

\section{Digestive tract parameters and immune organs}

Protein levels had no significant effects on chicks' digestive tract parameters and immune organs except for proventriculus and bursa of fabricius which were increased significantly by LPL (Table 9 and 10). The obtained results were in agreement with Si et al. (2004) who found that the relative weight of heart, gizzard, liver and the small intestine were unaffected by decreasing the dietary CP level. However, Ragab et al. (2012) reported no significant positive response on thymus and bursa of fabricius percentages when broiler chicks were fed diets vary in their CP content. Also, Dehghani-Tafti and Jahanian (2016) stated that the relative liver weight was decreased by reducing dietary CP level.

Also, OAT and OAL had no significant effects on all parameters studied except for bursa of fabricius and thymus, respectively. Diets containing CA recorded the higher $(P \leq 0.05)$ bursa \% compared with FUA diets. Besides, diets supplemented with $3 \%$ OA improved $(P \leq 0.05)$ thymus gland relative weight 
Table (6). Effects of crude protein levels and organic acids (types and levels) on caloric conversion ratio of broiler chicks during 0 to 6 weeks of age.

\begin{tabular}{|c|c|c|c|c|}
\hline \multirow{3}{*}{ Treatment } & \multicolumn{4}{|c|}{ Caloric conversion ratio (kcal ME/g gain) } \\
\hline & \multicolumn{4}{|c|}{ Periods, weeks } \\
\hline & Starter (0-3) & Grower (4-5) & Finisher $\left(6^{\text {th }}\right)$ & Total $(0-6)$ \\
\hline \multicolumn{5}{|l|}{ Main effects } \\
\hline${ }^{1} \mathrm{PL} \quad \mathrm{R}$ & $3.71^{\mathrm{b}} \pm 0.03$ & $5.38 \pm 0.12$ & $6.58^{\mathrm{a}} \pm 0.29$ & $4.92 \pm 0.09$ \\
\hline $\mathrm{L}$ & $3.93^{\mathrm{a}} \pm 0.04$ & $5.44 \pm 0.08$ & $5.76^{\mathrm{b}} \pm 0.12$ & $4.91 \pm 0.04$ \\
\hline P-value & $<.0001$ & 0.3345 & 0.0915 & 0.4904 \\
\hline${ }^{2} \mathrm{OAT}$ CA & $3.82 \pm 0.04$ & $5.37 \pm 0.09$ & $6.19 \pm 0.24$ & $4.90 \pm 0.08$ \\
\hline FUA & $3.83 \pm 0.04$ & $5.45 \pm 0.09$ & $6.15 \pm 0.24$ & $4.93 \pm 0.07$ \\
\hline P-value & 0.7019 & 0.4359 & 0.8241 & 0.5924 \\
\hline${ }^{3} \mathrm{OAL} \% \quad 0$ & $3.93^{\mathrm{a}} \pm 0.04$ & $5.64^{\mathrm{a}} \pm 0.10$ & $6.64^{\mathrm{a}} \pm 0.28$ & $5.13^{\mathrm{a}} \pm 0.07$ \\
\hline 1.5 & $3.67^{c} \pm 0.05$ & $5.12^{\mathrm{b}} \pm 0.12$ & $5.78^{\mathrm{b}} \pm 0.16$ & $4.67^{\mathrm{b}} \pm 0.06$ \\
\hline 3.0 & $3.77^{\mathrm{b}} \pm 0.05$ & $5.24^{\mathrm{b}} \pm 0.09$ & $6.62^{\mathrm{b}} \pm 0.18$ & $4.73^{\mathrm{b}} \pm 0.06$ \\
\hline $\mathrm{P}$-value & $<.0001$ & 0.0034 & 0.0035 & $<.0001$ \\
\hline Combined effects & & & & \\
\hline $\mathrm{RPL} \times \mathrm{OA} 0$ & $3.80^{\mathrm{b}} \pm 0.04$ & $5.71^{\mathrm{a}} \pm 0.25$ & $7.57^{\mathrm{a}} \pm 0.57$ & $5.25^{\mathrm{a}} \pm 0.19$ \\
\hline $\mathrm{RPL} \times \mathrm{CA} 1.5$ & $3.54^{\mathrm{cd}} \pm 0.09$ & $4.99^{\mathrm{ab}} \pm 0.26$ & $5.86^{\mathrm{b}} \pm 0.36$ & $4.57^{\mathrm{b}} \pm 0.08$ \\
\hline $\mathrm{RPL} \times \mathrm{CA} 3.0$ & $3.75^{\mathrm{bc}} \pm 0.10$ & $4.97^{\mathrm{ab}} \pm 0.11$ & $5.33^{\mathrm{b}} \pm 0.23$ & $4.57^{\mathrm{b}} \pm 0.03$ \\
\hline $\mathrm{RPL} \times \mathrm{OA} 0$ & $3.80^{\mathrm{b}} \pm 0.04$ & $5.71^{\mathrm{a}} \pm 0.25$ & $7.57^{\mathrm{a}} \pm 0.57$ & $5.25^{\mathrm{a}} \pm 0.19$ \\
\hline RPL $\times$ FUA 1.5 & $3.53^{\mathrm{d}} \pm 0.02$ & $4.86^{\mathrm{b}} \pm 0.11$ & $5.82^{\mathrm{b}} \pm 0.39$ & $4.51^{\mathrm{b}} \pm 0.03$ \\
\hline RPL $\times$ FUA 3.0 & $3.69^{\mathrm{bcd}} \pm 0.07$ & $5.38^{\mathrm{ab}} \pm 0.06$ & $5.36^{\mathrm{b}} \pm 0.20$ & $4.72^{\mathrm{b}} \pm 0.0 .01$ \\
\hline $\mathrm{LPL} \times \mathrm{OA} 0 \mathrm{LPL} \times$ & $4.06^{\mathrm{a}} \pm 0.06$ & $5.57^{\mathrm{ab}} \pm 0.15$ & $5.71^{\mathrm{b}} \pm 0.25$ & $5.00^{\mathrm{ab}} \pm 0.06$ \\
\hline CA 1.5 & $3.78^{\mathrm{b}} \pm 0.07$ & $5.17^{\mathrm{ab}} \pm 0.06$ & $5.60^{\mathrm{b}} \pm 0.34$ & $4.71^{\mathrm{b}} \pm 0.04$ \\
\hline $\mathrm{LPL} \times \mathrm{CA} 3.0$ & $3.76^{\mathrm{bc}} \pm 0.10$ & $5.29^{\mathrm{ab}} \pm 0.28$ & $6.20^{\mathrm{ab}} \pm 0.35$ & $4.82^{\mathrm{ab}} \pm 0.19$ \\
\hline $\mathrm{LPL} \times \mathrm{OA} 0$ & $4.06^{\mathrm{a}} \pm 0.06$ & $5.57^{\mathrm{ab}} \pm 0.15$ & $5.71^{\mathrm{b}} \pm 0.25$ & $5.00^{\mathrm{ab}} \pm 0.06$ \\
\hline LPL× FUA 1.5 & $3.82^{\mathrm{b}} \pm 0.03$ & $5.47^{\mathrm{ab}} \pm 0.34$ & $5.85^{\mathrm{b}} \pm 0.39$ & $4.90^{\mathrm{ab}} \pm 0.17$ \\
\hline LPL $\times$ FUA 3.0 & $3.88^{\mathrm{ab}} \pm 0.12$ & $5.34^{\mathrm{ab}} \pm 0.21$ & $5.59^{\mathrm{b}} \pm 0.51$ & $4.81^{\mathrm{ab}} \pm 0.11$ \\
\hline SEM & \pm 0.03 & \pm 0.07 & \pm 0.17 & \pm 0.05 \\
\hline $\mathrm{P}$-value & $<.0001$ & 0.1091 & 0.0014 & 0.0029 \\
\hline
\end{tabular}

compared with $1.5 \%$ OA diets. Significant differences were detected in the liver $\%$ and bursa $\%$ in response to the combined effects of PL, OAT and OAL (Table 9 and 10). The highest liver $\%$ was reported by RPL $+1.5 \% \mathrm{CA}$ diet compared with most of the treatments. On the other hand, the highest bursa \% was obtained by RPL+3\% CA while RPL+ $1.5 \%$ FUA gave the lowest percentage. Previous studies were inconsistent; Wickramasinghe et al. (2014) reported that 2\% dietary CA had no significant effect on the pancreas, gizzard and liver weights and ratios. Similarly, Nourmohammadi et al. (2010) showed that supplementation of 3 or $6 \%$ CA to broiler diet did not significantly affect liver weight. However, the relative weight of proventriculus and gizzard increased significantly by $6 \% \mathrm{CA}$. Also, Islam et al. (2008) concluded that the relative weights of heart, liver and spleen of broiler chickens were not affected by the dietary FUA (up to 7.5\%). In the same way, Ragab et al. (2012) found that there were no significant differences in thymus and bursa of fabricius $\%$ when broiler chicks fed diets different in PL and supplemented with $2 \%$ lactic or CA. Additionally, Ghazalah et al. (2011) concluded that broiler chicks fed $0.5 \%$ fumaric acid diet had a better immune response and disease resistance. This was due to improving the relative weight of primary lymphoid organs (spleen, bursa and thymus). Also, Adil et al. (2011b) concluded that birds fed diets supplemented with 2 or 3\% FUA had significant increases in length and weight of small intestines. Bursa and thymus are considered as a component of the immunity system (Sturkie, 1986) which is capable of producing immune cells and having the ability to protect birds from the invasion of pathological organisms.

\section{CONCLUSION}

Supplementation of CA or FUA acids, as feed additives, to broiler diets containing RPL improved productive performance, carcass traits and immune status. However, LPL supplemented diets tended to 
improve performance but the effects were inconsistent and insignificant. The effect of CA supplementation on ADG was obvious in the starter and finisher periods while FUA was better in the grower and total periods. Also, the present findings showed that reducing dietary CP level by $2 \%$ had no negative effect on ADG during the finisher and ADFI during starter. The influence of supplementation OA on dietary protein and amino acid requirements of different poultry species, however, needs further and extensive investigations.

Table (7). Effects of crude protein levels and organic acids (types and levels) on carcass characteristics (\% of live body weight) of broiler chicks at 42 days of age.

\begin{tabular}{|c|c|c|c|c|}
\hline \multirow[b]{2}{*}{ Treatments } & \multicolumn{4}{|c|}{ Carcass characteristics (\%) } \\
\hline & Inedible parts & Dressing & Giblets & Abdominal fat \\
\hline \multicolumn{5}{|l|}{ Main Effects } \\
\hline${ }^{1} \mathrm{PL} \quad \mathrm{R}$ & $22.52^{\mathrm{b}} \pm 0.20$ & $72.53^{\mathrm{a}} \pm 0.58$ & $3.86 \pm 0.06$ & $1.09^{\mathrm{b}} \pm 0.04$ \\
\hline $\mathrm{L}$ & $23.52^{\mathrm{a}} \pm 0.23$ & $71.17^{\mathrm{b}} \pm 0.54$ & $3.91 \pm 0.06$ & $1.40^{\mathrm{a}} \pm 0.05$ \\
\hline P-value & 0.0203 & 0.0007 & 0.7661 & $<.0001$ \\
\hline${ }^{2} \mathrm{OAT} \quad \mathrm{CA}$ & $22.98 \pm 0.23$ & $71.81 \pm 0.79$ & $3.96^{\mathrm{a}} \pm 0.06$ & $1.25 \pm 0.05$ \\
\hline FUA & $23.02 \pm 0.22$ & $71.93 \pm 0.62$ & $3.81^{\mathrm{b}} \pm 0.04$ & $1.24 \pm 0.05$ \\
\hline P-value & 0.4264 & 0.2926 & 0.0088 & 0.7228 \\
\hline${ }^{3} \mathrm{OAL} \% \quad 0$ & $23.53^{\mathrm{a}} \pm 0.21$ & $71.20^{c} \pm 0.61$ & $3.86 \pm 0.06$ & $1.41^{\mathrm{a}} \pm 0.05$ \\
\hline 1.5 & $21.82^{\mathrm{b}} \pm 0.24$ & $73.15^{\mathrm{a}} \pm 1.08$ & $4.00 \pm 0.10$ & $1.03^{\mathrm{b}} \pm 0.05$ \\
\hline 3 & $22.91^{\mathrm{a}} \pm 0.24$ & $72.10^{\mathrm{b}} \pm 0.89$ & $3.84 \pm 0.04$ & $1.15^{\mathrm{b}} \pm 0.05$ \\
\hline $\mathrm{P}$-value & $<.0001$ & $<.0001$ & 0.1823 & $<.0001$ \\
\hline \multicolumn{5}{|l|}{ Combined effects } \\
\hline $\mathrm{RPL} \times \mathrm{OA} 0$ & $22.98^{\mathrm{abc}} \pm 0.37$ & $72.08^{\mathrm{ab}} \pm 0.83$ & $3.72^{\mathrm{b}} \pm 0.08$ & $1.22^{\mathrm{bc}} \pm 0.06$ \\
\hline $\mathrm{RPL} \times \mathrm{CA} 1.5$ & $21.21^{\mathrm{ed}} \pm 0.67$ & $73.49^{\mathrm{a}} \pm 1.11$ & $4.52^{\mathrm{a}} \pm 0.19$ & $0.78^{\mathrm{d}} \pm 0.02$ \\
\hline $\mathrm{RPL} \times \mathrm{CA} 3.0$ & $22.26^{\mathrm{ed}} \pm 0.63$ & $72.75^{\mathrm{a}} \pm 1.63$ & $3.95^{\mathrm{b}} \pm 0.12$ & $1.04^{\mathrm{cd}} \pm 0.08$ \\
\hline $\mathrm{RPL} \times \mathrm{OA} 0$ & $22.98^{\mathrm{abc}} \pm 0.37$ & $72.08^{\mathrm{ab}} \pm 0.83$ & $3.72^{\mathrm{b}} \pm 0.08$ & $1.22^{\mathrm{bc}} \pm 0.06$ \\
\hline RPL $\times$ FUA 1.5 & $22.21^{\mathrm{ed}} \pm 0.35$ & $73.03^{\mathrm{a}} \pm 1.53$ & $3.78^{\mathrm{b}} \pm 0.09$ & $0.98^{\mathrm{cd}} \pm 0.06$ \\
\hline RPL $\times$ FUA 3.0 & $22.54^{\mathrm{bcd}} \pm 0.48$ & $72.65^{\mathrm{a}} \pm 1.99$ & $3.76^{\mathrm{b}} \pm 0.03$ & $1.05^{\mathrm{cd}} \pm 0.12$ \\
\hline $\mathrm{LPL} \times \mathrm{OA} 0$ & $24.10^{\mathrm{a}} \pm 0.42$ & $70.32^{c} \pm 0.69$ & $3.99^{\mathrm{b}} \pm 0.13$ & $1.59^{\mathrm{a}} \pm 0.09$ \\
\hline $\mathrm{LPL} \times \mathrm{CA} 1.5$ & $22.19^{\text {ed }} \pm 0.29$ & $72.67^{\mathrm{a}} \pm 2.23$ & $3.99^{\mathrm{b}} \pm 0.23$ & $1.15^{\mathrm{c}} \pm 0.12$ \\
\hline $\mathrm{LPL} \times \mathrm{CA} 3.0$ & $23.95^{\mathrm{ab}} \pm 0.21$ & $70.80^{\mathrm{bc}} \pm 1.05$ & $3.81^{\mathrm{b}} \pm 0.07$ & $1.44^{\mathrm{ab}} \pm 0.06$ \\
\hline $\mathrm{LPL} \times \mathrm{OA} 0$ & $24.10^{\mathrm{a}} \pm 0.42$ & $70.32^{c} \pm 0.69$ & $3.99^{\mathrm{b}} \pm 0.13$ & $1.59^{\mathrm{a}} \pm 0.09$ \\
\hline LPL $\times$ FUA 1.5 & $20.68^{\mathrm{e}} \pm 0.21$ & $74.40^{\mathrm{a}} \pm 1.36$ & $3.71^{\mathrm{b}} \pm 0.11$ & $1.21^{\mathrm{bc}} \pm 0.07$ \\
\hline LPL $\times$ FUA 3.0 & $22.91^{\mathrm{abc}} \pm 0.21$ & $72.19^{\mathrm{ab}} \pm 1.03$ & $3.83^{\mathrm{b}} \pm 0.05$ & $1.07^{\mathrm{c}} \pm 0.05$ \\
\hline SEM & \pm 0.16 & \pm 0.17 & \pm 0.04 & \pm 0.03 \\
\hline $\mathrm{P}$-value & $<.0001$ & $<.0001$ & 0.0025 & $<.0001$ \\
\hline
\end{tabular}


Table (8). Effects of crude protein levels and organic acids (types and levels) on meat and bone (\%) and meat to bone/fat ratios of broiler chicks at 42 days of age.

\begin{tabular}{|c|c|c|c|c|}
\hline Treatments & Meat $\%$ & Bone $\%$ & Meat:Bone & Meat:Fat \\
\hline \multicolumn{5}{|l|}{ Main Effects } \\
\hline${ }^{1} \mathrm{PL} \quad \mathrm{R}$ & $78.57^{\mathrm{a}} \pm 0.27$ & $21.43^{\mathrm{b}} \pm 0.27$ & $3.70^{\mathrm{a}} \pm 0.06$ & $19.56^{\mathrm{a}} \pm 0.58$ \\
\hline L & $76.47^{\mathrm{b}} \pm 0.35$ & $23.53^{\mathrm{a}} \pm 0.36$ & $3.29^{\mathrm{b}} \pm 0.06$ & $13.51^{\mathrm{b}} \pm 0.54$ \\
\hline $\mathrm{P}$-value & $<.0001$ & $<.0001$ & $<.0001$ & $<.0001$ \\
\hline${ }^{2} \mathrm{OAT} \quad \mathrm{CA}$ & $77.72 \pm 0.34$ & $22.28 \pm 0.35$ & $3.54 \pm 0.07$ & $16.76 \pm 0.79$ \\
\hline FUA & $77.33 \pm 0.35$ & $22.67 \pm 0.35$ & $3.46 \pm 0.07$ & $16.32 \pm 0.62$ \\
\hline P-value & 0.0967 & 0.1059 & 0.1053 & 0.4043 \\
\hline${ }^{3}$ OAL\% 0 & $78.59^{\mathrm{a}} \pm 0.26$ & $21.41^{\mathrm{b}} \pm 0.28$ & $3.71^{\mathrm{a}} \pm 0.06$ & $14.89^{c} \pm 0.61$ \\
\hline 1.5 & $77.91^{\mathrm{a}} \pm 0.30$ & $22.09^{\mathrm{b}} \pm 0.29$ & $3.55^{\mathrm{b}} \pm 0.06$ & $19.79^{\mathrm{a}} \pm 1.08$ \\
\hline 3.0 & $75.00^{\mathrm{b}} \pm 0.48$ & $25.00^{\mathrm{a}} \pm 0.48$ & $3.04^{\mathrm{c}} \pm 0.08$ & $16.59^{\mathrm{b}} \pm 0.89$ \\
\hline $\mathrm{P}$-value & $<.0001$ & $<.0001$ & $<.0001$ & $<.0001$ \\
\hline \multicolumn{5}{|l|}{ Combined effects } \\
\hline & $79.67^{\mathrm{a}} \pm 0.46$ & $20.33^{\mathrm{d}} \pm 0.46$ & $3.95^{\mathrm{a}} \pm 0.10$ & $18.19^{b c} \pm 0.83$ \\
\hline $\begin{array}{l}\mathrm{RPL} \times \mathrm{OA} 0 \\
\mathrm{RPL} \times \mathrm{CA} 1.5\end{array}$ & $78.75^{\mathrm{ab}} \pm 0.58$ & $21.25^{\mathrm{cd}} \pm 0.56$ & $3.73^{\mathrm{ab}} \pm 0.14$ & $25.40^{\mathrm{a}} \pm 1.11$ \\
\hline $\mathrm{RPL} \times \mathrm{CA} 3.0$ & $77.73^{b c} \pm 0.18$ & $22.27^{b c} \pm 0.18$ & $3.49^{b c} \pm 0.04$ & $19.42^{b c} \pm 1.63$ \\
\hline & $79.67^{\mathrm{a}} \pm 0.46$ & $20.33^{\mathrm{d}} \pm 0.46$ & $3.95^{\mathrm{a}} \pm 0.10$ & $18.19^{\mathrm{bc}} \pm 0.83$ \\
\hline $\begin{array}{l}\text { RPLX OA 0 } \\
\text { RPL } \times \text { FUA } 1.5\end{array}$ & $77.25^{\mathrm{bc}} \pm 0.42$ & $22.75^{\mathrm{bc}} \pm 0.42$ & $3.40^{\mathrm{bc}} \pm 0.09$ & $20.66^{\mathrm{b}} \pm 1.53$ \\
\hline RPL $\times$ FUA 3.0 & $76.15^{\mathrm{c}} \pm 0.64$ & $23.85^{\mathrm{b}} \pm 0.64$ & $3.21^{\mathrm{c}} \pm 0.12$ & $18.28^{\mathrm{bc}} \pm 1.99$ \\
\hline LPL $\times$ OA 0 & $77.50^{\mathrm{bc}} \pm 0.42$ & $22.50^{\mathrm{bc}} \pm 0.48$ & $3.47^{\mathrm{bc}} \pm 0.09$ & $11.59^{\mathrm{e}} \pm 0.69$ \\
\hline $\mathrm{LPL} \times \mathrm{CA} 1.5$ & $77.90^{\mathrm{b}} \pm 0.59$ & $22.10^{\mathrm{bc}} \pm 0.59$ & $3.54^{b c} \pm 0.13$ & $17.36^{\mathrm{bc}} \pm 2.23$ \\
\hline $\mathrm{LPL} \times \mathrm{CA} 3.0$ & $72.99^{\mathrm{d}} \pm 0.49$ & $27.01^{\mathrm{a}} \pm 0.49$ & $2.71^{\mathrm{d}} \pm 0.07$ & $12.32^{\mathrm{ed}} \pm 1.05$ \\
\hline LPL $\times$ OA 0 & $77.50^{\mathrm{bc}} \pm 0.42$ & $22.50^{\mathrm{bc}} \pm 0.48$ & $3.47^{b c} \pm 0.09$ & $11.59^{\mathrm{e}} \pm 0.69$ \\
\hline LPL× FUA 1.5 & $77.73^{b c} \pm 0.75$ & $22.27^{\mathrm{bc}} \pm 0.66$ & $3.51^{\mathrm{bc}} \pm 0.13$ & $15.72^{\mathrm{cd}} \pm 1.36$ \\
\hline LPL $\times$ FUA 3.0 & $73.12^{\mathrm{d}} \pm 0.57$ & $26.88^{\mathrm{a}} \pm 0.57$ & $2.73^{\mathrm{d}} \pm 0.08$ & $16.34^{\mathrm{c}} \pm 1.03$ \\
\hline SEM & \pm 0.25 & \pm 0.25 & \pm 0.05 & \pm 0.50 \\
\hline P-value & $<.0001$ & $<.0001$ & $<.0001$ & $<.0001$ \\
\hline
\end{tabular}


Table (9). Effects of crude protein levels, organic acids (types and levels) on the measurements of digestive tract (\% of live body weight) of broiler chicks at 42 days of age.

\begin{tabular}{|c|c|c|c|c|c|}
\hline \multirow[b]{2}{*}{ Treatments } & \multicolumn{4}{|c|}{ Digestive tract measurements (\%) } & \multirow{2}{*}{$\begin{array}{l}\text { Intestine length } \\
(\mathrm{cm})\end{array}$} \\
\hline & $\begin{array}{l}\text { Proven- } \\
\text { triculus }\end{array}$ & Gizzard & Liver & Intestine & \\
\hline \multicolumn{6}{|l|}{ Main Effects } \\
\hline${ }^{1} \mathrm{PL}$ & $0.314^{\mathrm{b}} \pm 0.006$ & $1.40 \pm 0.04$ & $2.13 \pm 0.04$ & $3.75 \pm 0.08$ & $178.83 \pm 2.02$ \\
\hline $\mathrm{L}$ & $0.331^{\mathrm{a}} \pm 0.006$ & $1.31 \pm 0.02$ & $2.09 \pm 0.04$ & $3.76 \pm 0.07$ & $179.00 \pm 1.81$ \\
\hline P-value & 0.0481 & 0.0892 & 0.3223 & 0.5527 & 0.8187 \\
\hline${ }^{2} \mathrm{OAT} \quad \mathrm{CA}$ & $0.323 \pm 0.005$ & $1.36 \pm 0.03$ & $2.14 \pm 0.05$ & $3.76 \pm 0.08$ & $179.75 \pm 1.92$ \\
\hline FUA & $0.322 \pm 0.007$ & $1.34 \pm 0.03$ & $2.07 \pm 0.03$ & $3.74 \pm 0.07$ & $178.08 \pm 1.91$ \\
\hline P-value & 0.8966 & 0.5177 & 0.2001 & 0.8205 & 0.4456 \\
\hline${ }^{3} \mathrm{OAL} \% \quad 0$ & $0.316 \pm 0.006$ & $1.37 \pm 0.04$ & $2.07 \pm 0.03$ & $3.73 \pm 0.08$ & $177.92 \pm 1.94$ \\
\hline 1.5 & $0.325 \pm 0.009$ & $1.32 \pm 0.04$ & $2.21 \pm 0.09$ & $3.74 \pm 0.13$ & $180.92 \pm 2.67$ \\
\hline 3.0 & $0.332 \pm 0.009$ & $1.36 \pm 0.03$ & $2.08 \pm 0.04$ & $3.83 \pm 0.10$ & $178.92 \pm 2.68$ \\
\hline P-value & 0.2783 & 0.6244 & 0.1577 & 0.7415 & 0.6740 \\
\hline Combined effects & & & & & \\
\hline $\mathrm{RPL} \times \mathrm{OA} 0$ & $0.308 \pm 0.011$ & $1.41 \pm 0.09$ & $2.06^{\mathrm{b}} \pm 0.08$ & $3.60 \pm 0.14$ & $176.58 \pm 4.77$ \\
\hline $\mathrm{RPL} \times \mathrm{CA} 1.5$ & $0.322 \pm 0.012$ & $1.47 \pm 0.09$ & $2.43^{\mathrm{a}} \pm 0.17$ & $3.81 \pm 0.38$ & $178.67 \pm 4.89$ \\
\hline $\mathrm{RPL} \times \mathrm{CA} 3.0$ & $0.314 \pm 0.012$ & $1.38 \pm 0.07$ & $2.14^{\mathrm{ab}} \pm 0.13$ & $3.84 \pm 0.20$ & $181.33 \pm 4.10$ \\
\hline $\mathrm{RPL} \times \mathrm{OA} 0$ & $0.308 \pm 0.011$ & $1.41 \pm 0.09$ & $2.06^{\mathrm{b}} \pm 0.08$ & $3.60 \pm 0.14$ & $176.58 \pm 4.77$ \\
\hline RPL $\times$ FUA 1.5 & $0.324 \pm 0.025$ & $1.33 \pm 0.11$ & $2.17^{\mathrm{ab}} \pm 0.07$ & $3.99 \pm 0.10$ & $186.67 \pm 4.77$ \\
\hline RPL $\times$ FUA 3.0 & $0.318 \pm 0.021$ & $1.34 \pm 0.03$ & $2.05^{\mathrm{b}} \pm 0.05$ & $3.95 \pm 0.31$ & $177.67 \pm 5.00$ \\
\hline $\mathrm{LPL} \times \mathrm{OA} 0$ & $0.325 \pm 0.011$ & $1.33 \pm 0.06$ & $2.08^{\mathrm{b}} \pm 0.04$ & $3.85 \pm 0.17$ & $179.25 \pm 3.03$ \\
\hline $\mathrm{LPL} \times \mathrm{CA} 1.5$ & $0.334 \pm 0.012$ & $1.24 \pm 0.02$ & $2.19^{\mathrm{ab}} \pm 0.28$ & $3.62 \pm 0.25$ & $179.83 \pm 7.38$ \\
\hline $\mathrm{LPL} \times \mathrm{CA} 3.0$ & $0.348 \pm 0.011$ & $1.35 \pm 0.08$ & $2.07^{\mathrm{b}} \pm 0.05$ & $3.95 \pm 0.10$ & $186.50 \pm 5.18$ \\
\hline $\mathrm{LPL} \times \mathrm{OA} 0$ & $0.325 \pm 0.011$ & $1.33 \pm 0.06$ & $2.08^{\mathrm{b}} \pm 0.04$ & $3.85 \pm 0.17$ & $179.25 \pm 3.03$ \\
\hline LPL $\times$ FUA 1.5 & $0.320 \pm 0.025$ & $1.22 \pm 0.02$ & $2.05^{\mathrm{b}} \pm 0.16$ & $3.58 \pm 0.23$ & $178.50 \pm 4.75$ \\
\hline LPL $\times$ FUA 3.0 & $0.349 \pm 0.023$ & $1.38 \pm 0.02$ & $2.06^{\mathrm{b}} \pm 0.05$ & $3.54 \pm 0.10$ & $170.17 \pm 5.94$ \\
\hline SEM & \pm 0.004 & \pm 0.02 & \pm 0.03 & \pm 0.06 & \pm 1.35 \\
\hline $\mathrm{P}$-value & 0.6456 & 0.7343 & 0.5263 & 0.7802 & 0.7581 \\
\hline
\end{tabular}


Table (10). Effects of crude protein levels, organic acids (types and levels) on the immune organs (\% of live body weight) of broiler chicks at 42 days of age.

\begin{tabular}{|c|c|c|c|}
\hline \multirow[b]{2}{*}{ Treatments } & \multicolumn{3}{|c|}{ Immune organs (\%) } \\
\hline & Spleen & Thymus & Bursa of fabricius \\
\hline \multicolumn{4}{|l|}{ Main Effects } \\
\hline${ }^{1} \mathrm{PL} \quad \mathrm{R}$ & $0.110 \pm 0.004$ & $0.294 \pm 0.014$ & $0.057^{\mathrm{b}} \pm 0.004$ \\
\hline $\mathrm{L}$ & $0.112 \pm 0.004$ & $0.306 \pm 0.015$ & $0.070^{\mathrm{a}} \pm 0.005$ \\
\hline P-value & 0.7023 & 0.5984 & 0.2943 \\
\hline${ }^{2} \mathrm{OAT}$ CA & $0.114 \pm 0.005$ & $0.304 \pm 0.015$ & $0.069^{\mathrm{a}} \pm 0.005$ \\
\hline FUA & $0.109 \pm 0.004$ & $0.297 \pm 0.014$ & $0.057^{\mathrm{b}} \pm 0.004$ \\
\hline $\mathrm{P}$-value & 0.3513 & 0.6605 & 0.0093 \\
\hline${ }^{3} \mathrm{OAL} \% \quad 0$ & $0.108 \pm 0.003$ & $0.295^{\mathrm{ab}} \pm 0.015$ & $0.065 \pm 0.004$ \\
\hline 1.5 & $0.116 \pm 0.008$ & $0.274^{\mathrm{b}} \pm 0.018$ & $0.056 \pm 0.005$ \\
\hline 3.0 & $0.113 \pm 0.007$ & $0.338^{\mathrm{a}} \pm 0.021$ & $0.068 \pm 0.007$ \\
\hline $\mathrm{P}$-value & 0.5394 & 0.0805 & 0.3235 \\
\hline Combined effects & & & \\
\hline $\mathrm{RPL} \times \mathrm{OA} 0$ & $0.108 \pm 0.007$ & $0.292 \pm 0.023$ & $0.050^{\mathrm{b}} \pm 0.005$ \\
\hline $\mathrm{RPL} \times \mathrm{CA} 1.5$ & $0.108 \pm 0.016$ & $0.258 \pm 0.054$ & $0.075^{\mathrm{ab}} \pm 0.014$ \\
\hline $\mathrm{RPL} \times \mathrm{CA} 3.0$ & $0.127 \pm 0.019$ & $0.362 \pm 0.042$ & $0.085^{\mathrm{a}} \pm 0.019$ \\
\hline $\mathrm{RPL} \times \mathrm{OA} 0$ & $0.108 \pm 0.007$ & $0.292 \pm 0.023$ & $0.050^{\mathrm{b}} \pm 0.005$ \\
\hline RPL $\times$ FUA 1.5 & $0.105 \pm 0.011$ & $0.243 \pm 0.033$ & $0.042^{\mathrm{b}} \pm 0.005$ \\
\hline RPL $\times$ FUA 3.0 & $0.112 \pm 0.008$ & $0.333 \pm 0.044$ & $0.055^{\mathrm{ab}} \pm 0.007$ \\
\hline $\mathrm{LPL} \times \mathrm{OA} 0$ & $0.108 \pm 0.005$ & $0.298 \pm 0.037$ & $0.079^{\mathrm{a}} \pm 0.010$ \\
\hline $\mathrm{LPL} \times \mathrm{CA} 1.5$ & $0.123 \pm 0.023$ & $0.298 \pm 0.034$ & $0.057^{\mathrm{ab}} \pm 0.007$ \\
\hline $\mathrm{LPL} \times \mathrm{CA} 3.0$ & $0.118 \pm 0.016$ & $0.337 \pm 0.041$ & $0.078^{\mathrm{a}} \pm 0.014$ \\
\hline $\mathrm{LPL} \times \mathrm{OA} 0$ & $0.108 \pm 0.005$ & $0.298 \pm 0.037$ & $0.079^{\mathrm{a}} \pm 0.010$ \\
\hline LPL× FUA 1.5 & $0.127 \pm 0.014$ & $0.295 \pm 0.025$ & $0.050^{\mathrm{ab}} \pm 0.013$ \\
\hline LPL $\times$ FUA 3.0 & $0.097 \pm 0.010$ & $0.325 \pm 0.046$ & $0.052^{\mathrm{ab}} \pm 0.010$ \\
\hline SEM & \pm 0.003 & \pm 0.010 & \pm 0.003 \\
\hline P-value & 0.8177 & 0.8076 & 0.0123 \\
\hline
\end{tabular}

\section{REFERENCES}

Adil, S.; M.T Banday; G.A. Bhat; M.S. Mir. and M. Rehman (2010). Effect of dietary supplementation of organic acids on performance, intestinal histomorphology, and serum biochemistry of broiler chicken. Vet. Med. Int, 7 pages. doi: 10.4061/2010/479485.

Adil, S.; M.T. Banday; G.A. Bhat; S.D. Qureshi and S.A. Wani (2011a). Effect of supplemental organic acids on growth performance and gut microbial population of broiler chicken. Livestock Res. Rural Dev., 23, Article \#6. http://www.lrrd.org/lrrd23/1/adil23006.htm

Adil, S.; T. Banday; G.A. Bhat; M. Salahuddin; M. RaquIb and S. Shanaz (2011b). Response of broiler chicken to dietary supplementation of organic acids. J. Central European Agri., 12: 498-508.

Ahsan-ul-Haq, M.T.C.; F. Ahmad; J. Shafi and M. Ashraf (2014). Effect of dietary acidification with citric acid on carcass characteristics, haemogram and serum metabolite values of broiler chicken. Pakistan J. Life and Social Sci., 12: 36-41.

A.O.A.C. (1990). Association of Official Analytical Chemists. Official Methods of Analysis, 15th Edition. Washington, DC, USA.

Azarnik, A.; M. Bojarpour; M. Eslami; M.R. Ghorbani and K. Mirzadeh (2010). The effect of different levels of diet protein on broilers performance in ad libitum and feed restriction methods. J. Anim. Vet. Adv, 9: 631-634.

Brzoska, F.; B. Sliwinski and O. Michalik-Rutkowska (2013). Effect of dietary acidifier on growth, mortality, post-slaughter parameters and meat composition of broiler chickens. Annals of Anim. Sci., 13: $85-96$. 
Dehghani-Tafti, N. and R. Jahanian (2016). Effect of supplemental organic acids on performance, carcass characteristics, and serum biochemical metabolites in broilers fed diets containing different crude protein levels. Anim. Feed Sci. Technol., 211:109-116.

Duncan, D.B. (1955). Multiple range and multiple F tests. Biometrics, 11: 1-42.

Fascina, V.B.; J.R. Sartori; E. Gonzales; F. Barros De Carvalho; I.M.G. Pereira De Souza; G. V. Polycarpo; A.C. Stradiotti and V.C. Pelícia (2012). Phytogenic additives and organic acids in broiler chicken diets. Revista Brasileira de Zootecnia. 41: 2189-2197.

Food and Agriculture Organization of the United Nations, FAO (2012).

Furuse, M. and H. Yokota (1985). Effect of the gut microflora on chick growth and utilization of protein and energy at different concentrations of dietary protein. Br. Poult. Sci., 26: 97-104

Ghazalah, A.A.; A.M. Atta; M.EL. Kout Elkloup, Moustafa and F. H. Riry, Shata (2011). Effect of dietary supplementation of organic acids on performance, nutrients digestibility and health of broiler chicks. Inter. J. Poult. sci., 10: 176-184.

Hernández, F.; V. García; J. Madrid; J. Orengo; P. Catalá and M.D. Megías (2006). Effect of formic acid on performance, digestibility, intestinal histo-morphology and plasma metabolite levels of broiler chickens. Br. Poult. Sci., 47: 50-67.

Houshmand, M.; K. Azhar; I. Zulkifli; M.H. Bejo and A. Kamyab (2012). Effects of non-antibiotic feed additives on performance, immunity and intestinal morphology of broilers fed different levels of protein. South Afr. J. Anim. Sci., 42: 22-32.

Huwaida, E.E.M.; H.O.S. Rashid; A.Y. Ibrahim and K.M. Elamin (2013). Effect of dietary protein level and strain on carcass characteristics of heat stressed broiler chicks. Agri. \& Biol. J. North America, 4: 504-511.

Islam K.M.S.; A. Schuhmacher; H. Aupperle and J.M. Gropp (2008). Fumaric acid in broiler nutrition: A dose titration study and safety aspects. Int. J. Poult. Sci, 7: 903-907.

Kamran Z; M. Nisa; M.A. Nadeem; M. Sarwar; S.S. Amjid; R.H. Pasha and M.S. Nazir (2011). Effect of low crude protein diets with constant metabolizable energy on performance of broiler chickens from one to thirty-five days of age. Indian J. Anim. Sci., 81: 1165-1172.

Leeson, S. and J.D. Summers (2001). Scott's Nutrition of the Chickens. 4th Ed, University Book, Guelph, Ontario, Canada.

Mohammadagheri, N.; R. Najafi and G. Najafi (2016). Effects of dietary supplementation of organic acids and phytase on performance and intestinal histomorphology of broilers. Vet. Res. Forum, 7: 189-195.

National Research Council, NRC, 1994. Nutrient Requirements of Poultry, 9th revised Ed. National Academic Press. Washington, D.C., USA.

Nourmohammadi, R.; S.M. Hosseini and H. Farhangfar (2010). Influence of citric acid and microbial phytase on growth performance and carcass characteristics of broiler chickens. American J. Anim. \& Vet. Sci., 5: 282-288.

Ragab, M.S.; H.M. Abdel wahed; E.M. Omar and W.H.A. Mohamed (2012). Effect of adding citric and lactic acids to broiler diets different in their protein content on productive performance, bacterial count and some blood parameters. Egyptian J. Nutrition and feeds, 15: 613-629.

Ricke, S.C. (2003). Perspectives on the use of organic acids and short chain fatty acids as antimicrobials. Poult. Sci., 82(4):632-639.

SAS (2006). Statistical Analysis System, SAS User's Guide: Statistics. SAS Institute Inc. Editors, Cary, NC.

Si, J.; C.A. Fritts; D.J. Burnham and P.W Waldroup (2004). Extent to which crude protein may be reduced in corn-soybean meal broiler diets through amino acid supplementation. Int. J. Poult. Sci, 3: 46-50.

Sturkie, P.D. (1986). “Avian Physiology”. 4th ed. Springer-Verlag, Inc., New Work, NY.

Vander Klis, J.D. and A.J.M. Jansman (2002). Optimising nutrient digestion, absorption and gut barrier function in monogastrics: reality or illusion? In: Blok, M.C.; H.A. Vahi; L. de Braak; G. Hemke and M. Hessing (Eds.), Nutrition and health of the gastrointestinal tract. Wageningen Academic Publishers, the Netherlands, pp: 15-36.

Wickramasinghe, K.P.; N.S.B.M. Atapattu and R.T. Seresinhe (2014). Effects of Citric Acid on Growth Performance and Nutrient Retention of Broiler Chicken Fed Diets Having Two Levels of Non-Phytate Phosphorus and Rice Bran. Iranian J. Applied Anim. Sci., 4: 809-815.

Widyaratne, G.P. and M.D. Drew (2011). Effects of protein level and digestibility on the growth and carcass characteristics of broiler chickens1. Poult. Sci., 90: 595-603. 


\section{Attia et al.}

Wolfenden, A.D.; J.L. Vicente; J.P. Higgins; R.L. Andreath Filho; S.E. Higgins; B.M. Hargis and G. Tellez (2007). Effect of organic acids and probiotics on Salmoneila enteritidis infection in broiler chickens. Int. J. Poult. Sci., 6: 403-405.

كتاكيت اللتمثراخلي لبروتين العليقة والاحماض العضوية على آداء النمو وصفات الذبيحة وأعضاء المناعة فى

$$
\begin{aligned}
& \text { فاتن عبد العزيز محمود عطية و هيام سيد عبد الطليم و حماده صلاح صابر عحم و إسماعيل حافظ هرمس } \\
& \text { قسم الإتتاج العيواني والثروة السمكية ـ كلية الزراعة - الإسماعلية - جامعة قناة السويس }
\end{aligned}
$$

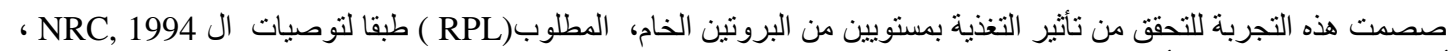

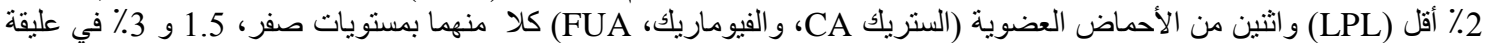

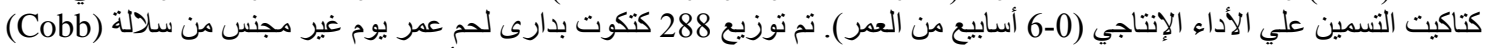

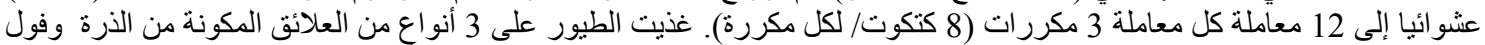

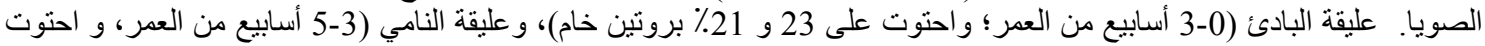

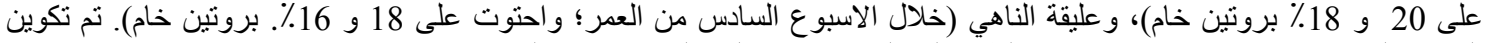

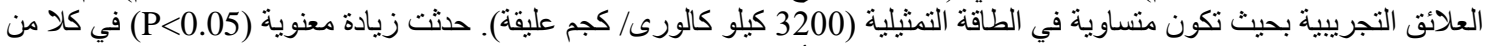

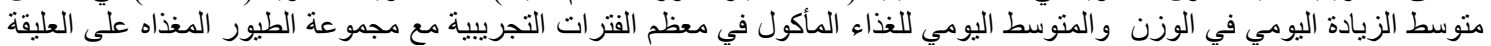

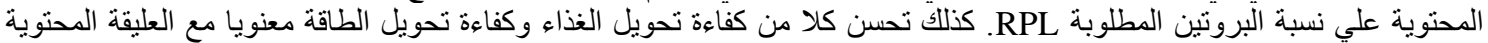

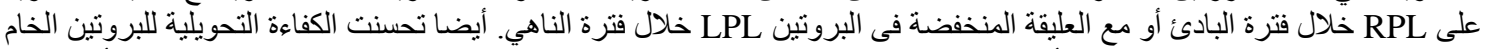

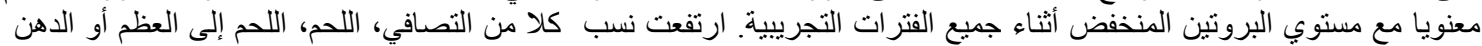

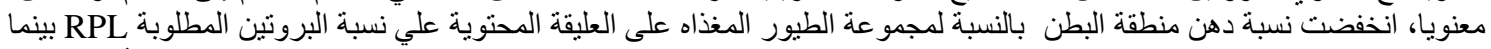

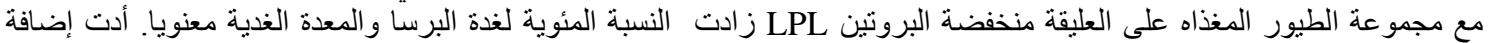

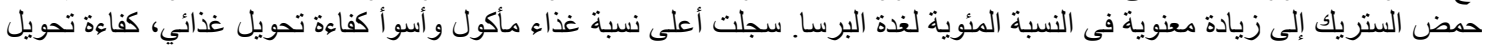

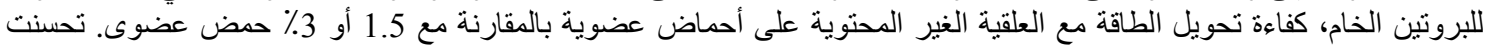

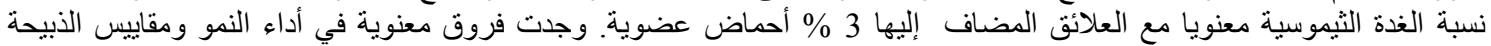

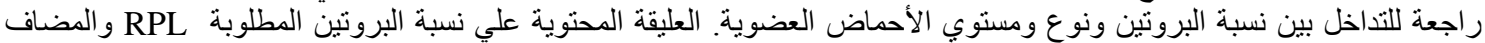

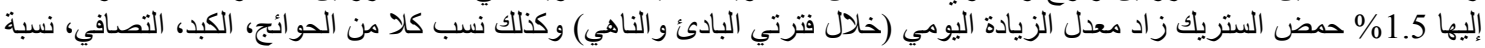

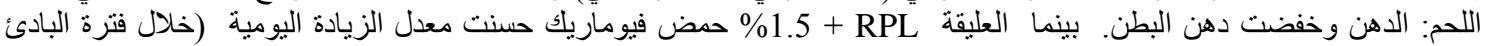

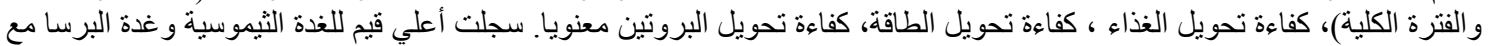

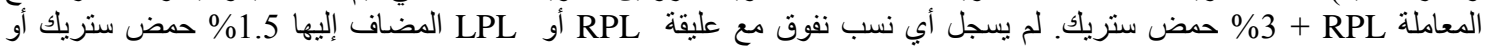

